Olivet Nazarene University

Digital Commons @ Olivet

$5-2015$

\title{
Relationship of Ethical Knowledge to Action in Senior Baccalaureate Nursing Students
}

Catherine S. Moe

Olivet Nazarene University, sckesmoe@hotmail.com

Follow this and additional works at: https://digitalcommons.olivet.edu/edd_diss

Part of the Bioethics and Medical Ethics Commons, Curriculum and Social Inquiry Commons, Ethics and Political Philosophy Commons, Ethics in Religion Commons, Nursing Commons, and the Social and Philosophical Foundations of Education Commons

\section{(c) (i)}

This work is licensed under a Creative Commons Attribution 4.0 License.

\section{Recommended Citation}

Moe, Catherine S., "Relationship of Ethical Knowledge to Action in Senior Baccalaureate Nursing Students" (2015). Ed.D. Dissertations. 83.

https://digitalcommons.olivet.edu/edd_diss/83

This Dissertation is brought to you for free and open access by the School of Graduate and Continuing Studies at Digital Commons @ Olivet. It has been accepted for inclusion in Ed.D. Dissertations by an authorized administrator of Digital Commons @ Olivet. For more information, please contact digitalcommons@olivet.edu. 


\title{
RELATIONSHIP OF ETHICAL KNOWLEDGE TO ACTION IN SENIOR BACCALAUREATE NURSING STUDENTS
}

by

\author{
Catherine S. Moe
}

\begin{abstract}
Submitted to the Faculty of
Olivet Nazarene University

School of Graduate and Continuing Studies

in Partial Fulfillment of the Requirements for

the Degree of
\end{abstract}

Doctor of Education

in

Ethical Leadership

May 2015 
RELATIONSHIP OF ETHICAL KNOWLEDGE TO ACTION

IN SENIOR BACCALAUREATE NURSING STUDENTS

by

Catherine S. Moe

Dissertation
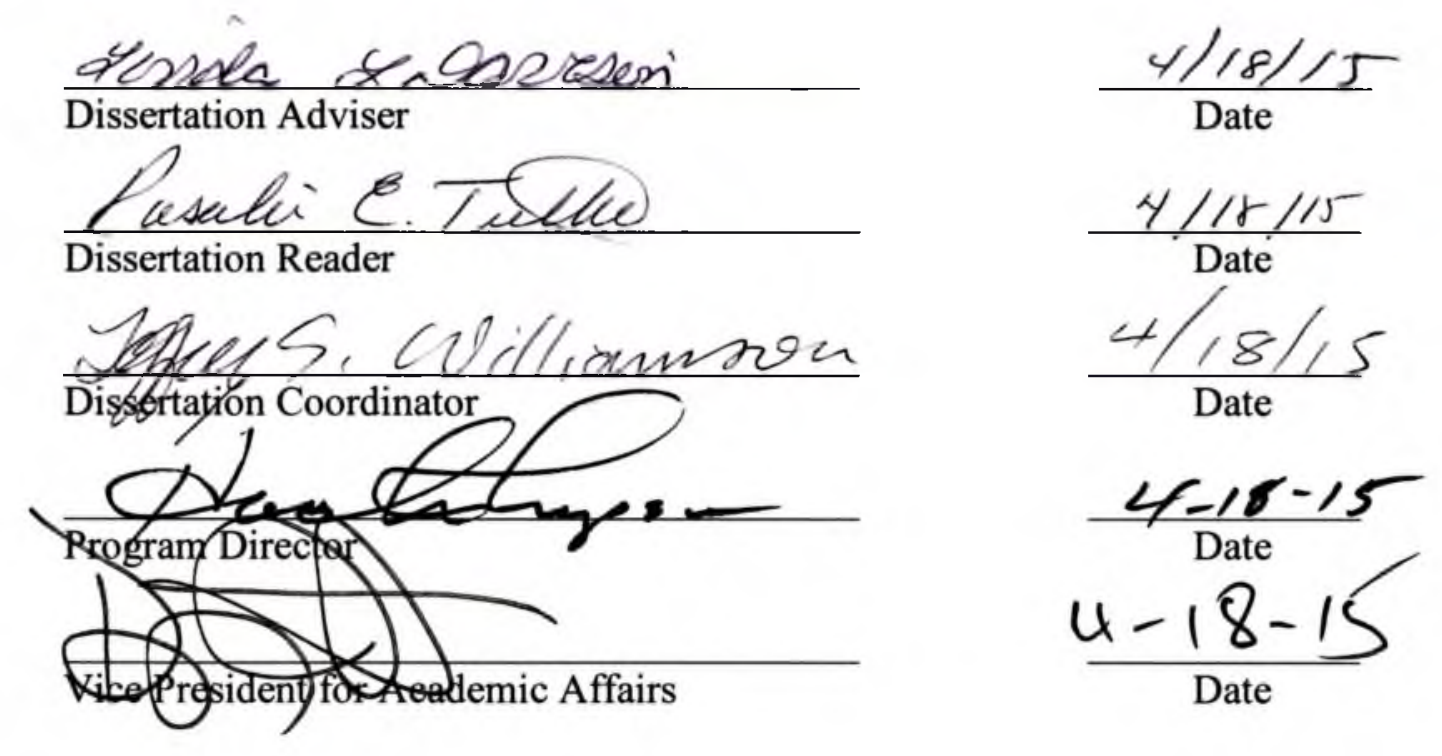
(C) 2015

Catherine S. Moe

All Rights Reserved 


\section{ACKNOWLEDGMENTS}

Completing the requirements for an advanced degree, especially at the doctoral level is a major challenge. The process has not been easy but it has been rewarding. My support network consists of a village of family and friends who have been behind me all of the way - despite thinking I was crazy to attempt it. My husband Scott, daughters Sarah and Ellen, son Kyle, sister Tish, and my parents Joan Smith and Chuck Smith have been significantly inconvenienced through this journey but always expressed their pride in me and my work plus helped when possible.

In addition to my family, I am especially and forever indebted Dr. Margie Williams. She served unofficially as coach, reader, and advisor; often at the last minute. In addition to helping me with this project, she serves as my mentor and, most importantly, she is my friend. Other friends I am grateful to include: Mallory, Charlotte, and my Bible Study group. Mallory encouraged me to begin my journey and lent me an ear when it was needed despite her own personal challenges. Charlotte traveled with me, listened to my frustrations, and helped me outline several assignments in the car. My Bible Study group, affectionately known as the Bible Babes, is a group of women who have been a part of my life for over 25 years. Their weekly support and encouragement served to maintain my motivation when the journey was difficult. Together we have faced many challenges and I know this group of women is indomitable. With their force behind me I had no choice but to be successful. Lastly, I need to acknowledge the work of my advisor Dr. Linda Davisson. Linda gave timely feedback and guidance but 
allowed me to proceed at my own pace and in my own way. Although there were times when I thought I wanted more direction she seemed to know that I really did not, making her style was perfect for me.

Last, I need to acknowledge the people who took the journey with me and were with me every step of the way. The cohort I was randomly assigned helped me to grow as a person into a more gentle and calm individual. Without the presence of these very special people at every class I might have stopped my journey. This experience reinforced the presence of a power beyond what I can see or even understand and strengthened my faith. 


\begin{abstract}
Nursing educators are expected to prepare students to practice in a complex health care environment yet nursing curriculums vary in how the ethical reasoning ability of students is developed. To effectively manage clinical situations that have ethical implications, practitioners need to be able to recognizing these situations and have the ability to take action. Using an established instrument known as Ketefian's Judgments About Nursing Decisions (JAND) to survey nursing students, this study examined the relationship between knowledge of the Code of Ethics for Nurses to choices of action in senior nursing students in baccalaureate nursing programs enrolled in the last semester of classes before graduating. The research process also included exploration of individual characteristics of the students to determine what impact, if any, these had on the relationship between knowledge and choice of action. There was a positive, significant, correlation between knowledge and action in senior baccalaureate nursing students. There was no significant difference in this relationship as a result of education or experience within the student group but a large discrepancy in the numbers of participants in each group may have impacted this finding. Thus college credit in courses on ethics, previous experience with making health care decisions, and general experience in health care did not significantly impact this relationship, but did indicate a need for further research.
\end{abstract}




\section{TABLE OF CONTENTS}

Chapter Page

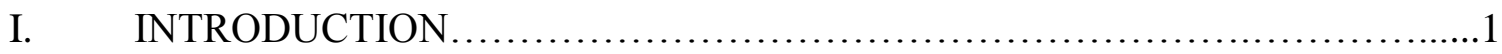

Statement of the Problem.................................................... 3

Background..............................................................

Research Questions..................................................6

Definition of Terms...................................................

Significance of the Study...........................................

Process to Accomplish.............................................. 10

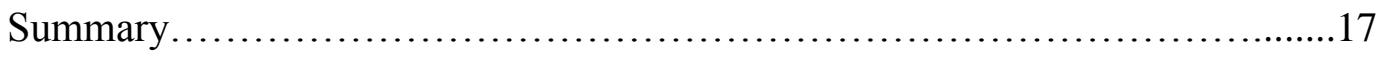

II REVIEW OF THE LITERATURE...................................19

Introduction...................................................... 19

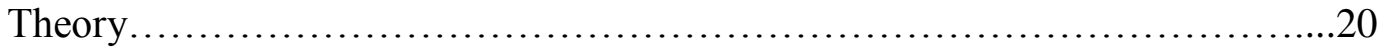

Description of Ethics in Nursing......................................23

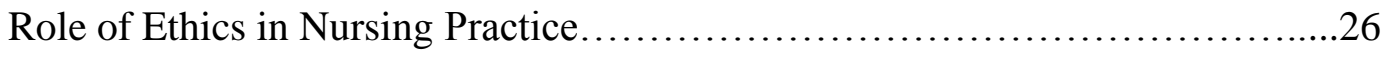

Overview of Educational Methods.......................................29

Impact of Ethics Education...........................................39

Conclusion.......................................................44

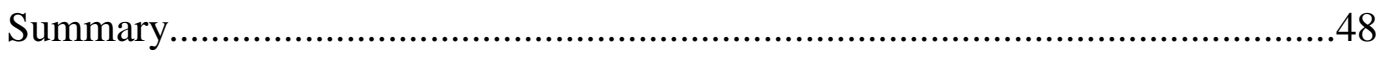

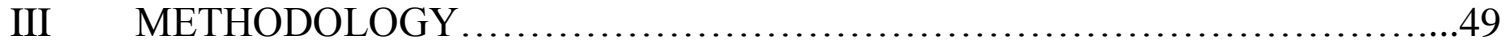

Introduction......................................................49

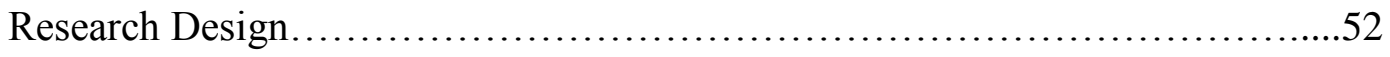


Population........................................................57

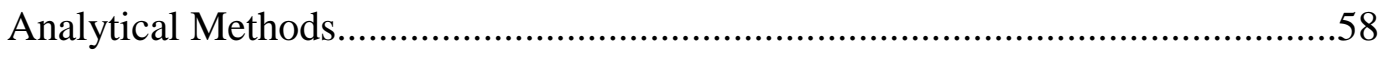

Data Collection.....................................................61

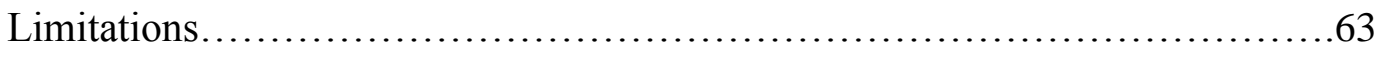

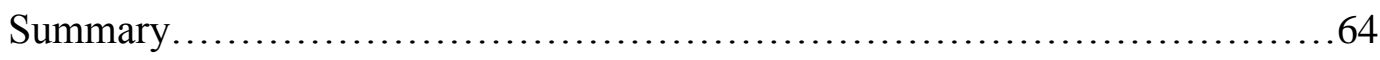

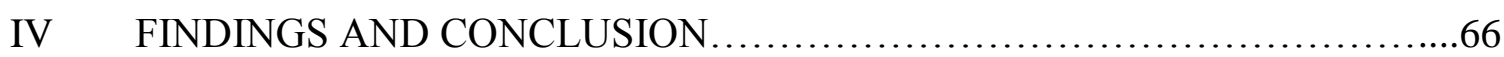

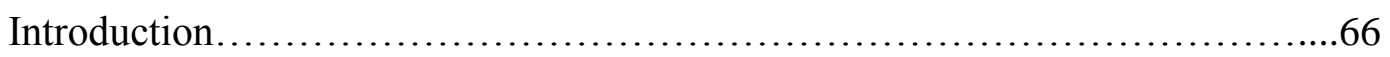

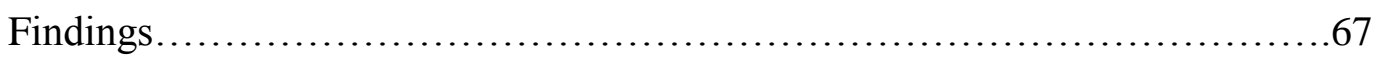

Conclusions............................................................

Implications and Recommendations................................... 75

REFERENCES .................................................79 APPENDIXES

A. Assessment of Individual Characteristics...............................88

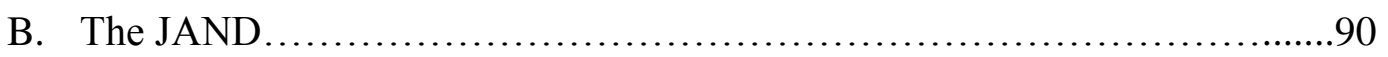




\section{LIST OF TABLES}

Table $\quad$ Page

1. Ethnicity of the Sample Population.......................................................59

2. Representation by Gender of Participants.................................................60

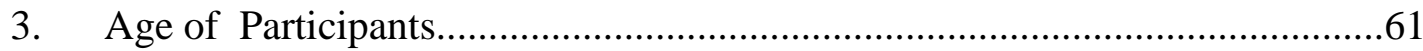

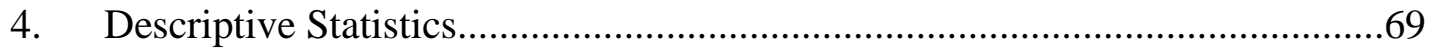

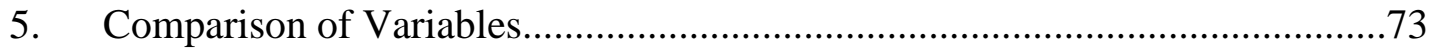




\section{LIST OF FIGURES}

Figure $\quad$ Page

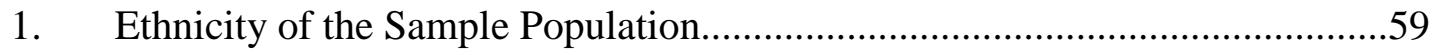

2. Representation of Gender of Participants................................................60

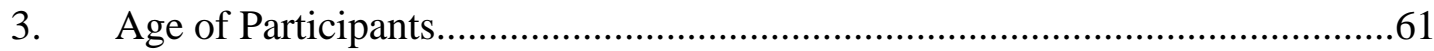

4. Correlation of Knowledge to Action............................................................69 


\section{CHAPTER I}

\section{INTRODUCTION}

Ethics is a component of nursing that impacts all aspects of practice. Health care professionals, especially nurses, address life and death situations when providing care for their patients. People, when they are patients, trust their lives and general health to the nurses that are responsible for their care. This trust requires that nurses carry out all responsibilities without the influence of their personal beliefs and values (Dinç \& Görgülü, 2002). Adhering to an ethical practice is a required component of nursing education as described by American Association of Colleges of Nursing (2008) and specifically delineated in Essential VIII-Professionalism and Professional Values. In the rationale for Essential VIII, it is stated that baccalaureate graduates should be prepared to respond to numerous dilemmas and to make decisions within an ethical framework. Understanding the values that are brought to the relationship by each patient and anyone else involved in patient care is crucial to the quality of care. In addition to being an expectation of professional behavior, honesty and ethical practice impact patient safety (American Association of Colleges of Nursing).

Education in ethics and ethical theory provides the nurse with tools to reflect critically on the care they provide in their practice (Vanlaere \& Gastmans, 2007). Educators in nursing curriculums are responsible for and challenged to prepare students to practice in the complex health care environment. Since the work of nursing impacts 
lives, it is imperative that students are educated and socialized to make ethical decisions (Turner \& Bechtel, 1998). This includes preparation that enables nurses to assist patients to make tough decisions that are reflective of the patient's values and include the choices every patient has regarding his or her care. Dierckx de Casterlé, Izumi, Godfrey, and Denhaerynck (2008) reinforced that health care is complex and that many clinical situations often require complex solutions. Dyess and Sherman (2009) determined that new graduates struggle with a lack of confidence and feeling overwhelmed. New graduates reported the expectation that they needed to make important decisions very quickly which resulted experiencing chaos and feeling overwhelmed. Clear judgment and the ability to think critically are essential and new graduates can feel unprepared to meet many of the challenges faced in providing patient care.

The intent of ethics education of nursing students is to develop skilled practitioners capable of detecting and responding to the ethical issues faced by nurses in practice. Active participation by the student facilitates this process (Görgülü \& Dinç, 2007). Nurses encounter difficult clinical situations daily; frequently assisting patients in making challenging decisions about their care or the care of a family member. The characteristics of nursing practice require that nursing students are capable of thinking ethically because they experience dilemmas in everyday situations (Hunink, van Leeuwen, Jansen, \& Jochemsen, 2009). Many clinical situations have ethical considerations that influence the choice of outcomes or solutions; often there is not a single solution appropriate for all clients (Lemonidou, Papathanassoglou, Giannakopoilou, Patiraki, \& Papadatou, 2004). To be able to practice as a professional nurse requires the ability make ethical decisions (Dinç \& Görgülü, 2002) 
Nurses in practice face ethical challenges more and more frequently. Progress in health care technology, global developments, and the graying of the population are factors influential to this trend (Dinç \& Görgülü, 2002; Görgülü \& Dinç, 2007; Hsu, 2011). When faced with complex care situations, nurses are expected to make autonomous decisions regarding the delivery of care to their patients within rigid time constraints (Goethals, Gastmans, \& Dierckx de Casterle, 2010). Nurses report a lack of confidence in the decision-making process when choosing a course of action when faced with ethical dilemmas (Ham, 2004). The complexity of health care and increased incidence of ethical challenges in nursing practice support the need for student nurses to develop ethical reasoning ability in order to be prepared to manage clinical situations with ethical considerations in their practice after graduation (Dinç \& Görgülü; Görgülü \& Dinç; Hsu).

\section{Statement of the Problem}

Nursing curriculums vary in how the ethical reasoning ability of students is developed. Some nursing programs require an ethics of health care course; others require a generic ethics course that is not specific to nursing or even health care. Other nursing programs embed the content throughout all courses in the curriculum, and some include instruction on ethical principles only if situations are encountered during a clinical practicum. Whether or not nursing students are adequately prepared to make ethical decisions at the time of graduation is not clear (Dierckx de Casterlé, Grypodonck, Vuylsteke-Wauters, \& Janssen, 1997; Krawczyk, 1997; Nolan \& Markert, 2002). The ability to make decisions that are ethically based is often learned through practice; consequently, students who were fortunate to encounter ethical situations through their 
clinical practicum would have an advantage over students who did not. This approach results in students who possess a cursory knowledge of ethical practice. Schools that expect all faculty members to teach ethics without supporting the development of the faculty experience similar results (Hamric, 2001; Ketefian, 1999). Doane (2002) reinforced that ethics is a deeply personal process embedded in the work of nursing, making the development of pedagogy for student instruction challenging.

Iglesias, Vallejo, Cena, and Fuentes (2011) conducted a study where the authors evaluated nursing students' understanding and attitudes about bioethical dilemmas. The students were knowledgeable about some but not all of the issues identified. Analysis of these results implied a deficiency in the nursing curriculum regarding bioethical issues. The students tended to be neutral on the issues most unfamiliar to them. These authors expressed concern that lack of knowledge would impact the students' practice, and recommended that additional content on ethics be added the curriculum.

Incentive to conduct this study originated from the scarcity of research on this subject and findings acknowledged by researchers like Ulrich et al. (2010) who concluded that nurses with less than five years of experience reported higher levels of stress associated with managing ethical issues encountered in their practice than nurses who had more than five years of experience. The purpose of this research was to examine the relationship between knowledge of the Code of Ethics for Nurses of graduating nursing students to choices of action in order to guide the educational process of nursing students. The research process included exploration of individual characteristics that also potentially contributed to the students' knowledge and choice of action. 


\section{Background}

The history of nursing's ethical code is described by Fowler (2008) in the American Nurses Association's (ANA) Guide to the Code of Ethics and summarized here. Although the ANA formally adopted the first official code of ethics in 1950, the Florence Nightingale Pledge, written in 1893 by Lystra Greer, is generally considered to be the first code of ethics in nursing. Between 1893 and1950, nursing professionals made several attempts to create a standard of practice with respect to ethics, but were not able to reach consensus within the professional organizations. Once the first code was adopted in 1950, focus shifted to enforcement of the principles contained within it. The next revision occurred in 1968 and addressed the importance of the nurse adhering to the standards of the profession (Fowler).

Often the magnitude and complexity of the legal and ethical issues exceeded the regulation available through the Codes of Ethics (Turner \& Bechtel, 1998). Additional revisions occurred over the next several years and the adjustments reflected changes in autonomy of the nursing role, access to health care as a right of all, increased focus on global influences in health, a patient's level of involvement in his or her own care, and ultimately the relationship between the personal and professional ethics of a nurse. The current Code of Ethics is fluid in use of terminology, allowing accommodation of changes in practice settings and new venues of nursing without requiring revision (Fowler, 2008).

As educators, it is important to assist graduating nurses to develop their ability to reason in an ethical manner. Efforts to promote ethics education in nursing have been intensified in recent years, and necessary learning experiences that result in the 
achievement of desired outcomes related to ethics has been a major concern among nursing programs (Park, Kjervik, Crandell, \& Oerman 2012). Students cannot depend on chance exposure to a clinical situation in order to develop ethical reasoning abilities. Nursing has an obligation to teach ethical decision making (Turner \& Bechtel, 1998). Instruction in the theory of ethics to nursing students, along with exposure to ethical dilemmas in a clinical environment, is necessary to prepare safe and competent practitioners who are able to manage clinical situations with ethical considerations.

Through analysis of reflective essays, Beckett, Gilbertson, and Greenwood (2007) examined the clinical experiences of second-year baccalaureate nursing students and discovered that the students possessed advanced relational skills enabling recognition and response to ethical situations. Callister, Luthy, Thompson, and Memmott (2009) described and analyzed the ethical reasoning ability of 70 baccalaureate nursing students and identified that the students showed an understanding of ethical reasoning and behavior, but not mastery of these skills. Nolan and Markert (2002) indicated that nursing students should be taught that there will be occasions where their personal code of ethics will conflict with practice. Nursing students need opportunities that facilitate development in moral and ethical reasoning. These experiences facilitate the development of nurses to practice within the framework of the American Nurses Association Code of Ethics. (Wehrwein, 1990).

\section{Research Questions}

1. What is the relationship between knowledge of the Code of Ethics and choice of action in given scenarios by senior baccalaureate nursing students? 
2. What impact does previous coursework on ethical content have on the relationship between knowledge of the Code of Ethics and choice of action in given scenarios?

3. What impact does previous clinical experience with ethical situations have on the relationship between knowledge of the Code of Ethics and choice of action in given scenarios?

\section{Definition of Terms}

Ethics. A general term referring to a sub-theory of the subject of philosophy that is primarily concerned with understanding moral attributes of life and what is good or right (Gibson, 1993; Scanlon, 1995).

Nursing ethics. Branch of applied ethics that is inclusive of the norms, values, and principles that guide the decisions and actions of those who practice within the nursing profession (Scanlon, 1995).

Ethical dilemma. A situation where conflict exists between the values or choices of action and arguments can be made for either position (Cooper, 2004; Gibson, 1993).

Code of Ethics. A document that explicitly defines and describes the primary goals, values, and obligations of the nursing profession (Fowler, 2008).

Significance of the Study

Arman and Rehnsfeldt (2007) described how caring theory is directly related to ethical care. When a nurse approaches a patient from the patient's belief structure, he or she is providing care that is ethical. It is the emphasis on the patient and his or her welfare that helps to convert caring into ethical care. Ideal caring involves crossing into private areas; doing what is necessary to assist the patient, not staying within the rules 
and boundaries simply to be compliant with them. It also means doing what is best for the patient. Patients feel they are important when their needs are recognized and incorporated into the treatments. Recognition of the role caring plays in the definition of ethical care helps to define specific behaviors, assists nursing faculty to teach the behaviors, and then recognizes the behaviors in the student (Arman \& Rehnsfeldt). Additionally, ethical practice is more than knowing and understanding, action needs to follow. The student must be confident and capable of implementing the actions necessary to fulfill the ethical needs of the patient. Dierckx de Casterlé, Janssen, and Grypodonck (1996) explained ethical nursing practice as a link to action, stating that reasoning and implementation of action both need to be present and ethical.

Candela and Bowles, (2008) made it clear that there continues to be a dichotomy between practice and education. Entering the workforce as a new nurse can be overwhelming. Orientation programs are costly and employers continue to affirm that graduates do not seem ready for the workplace. The technology expansion and the dynamics of health care contribute to the educators' position that practice should not expect a finished product (Candela \& Bowles). While ethics is not a science with verifiable answers, an understanding of ethical theory enables a nurse to practice in a comprehensive manner (Gibson, 1993). In order for nursing students to be prepared to practice effectively in clinical situations where ethical implications exist, the education process needs to be effective. Students need to be able to address and effectively manage ethical situations while they are students to ensure they can manage them as professionals (Cameron, Schaffer, \& Park, 2001). 
Often nurse educators are not aware of how new graduates perceive their entry into practice and may actually hear how students are unprepared to meet the needs of employers (Beckett, et al., 2007). New nurses and nursing students may feel and express a sense of not being prepared because of a perceived lack of technical skills. The focus nursing students have on procedures and the ability to perform technical skills may obscure achievements in relational areas thus impacting the professional identity of the new nurse (Beckett, et al.). Beginners or novices without experience use rules to guide them in making decisions. As novices, nurses frequently lack the ability to use discretionary judgment, using rules unrelated to the context of the situation to guide behavior and decisions (Benner, 1982). In addition to recognizing when an ethical dilemma exists, the nurse must also possess confidence to act on the assessment (Gaul, 1987).

Educational programs are designed to prepare generalists in practice but the generalist should be able to manage specific clinical circumstances consistent with the expectations of employers. Faculty members of schools or colleges of nursing have the responsibility to guide the transition of knowledge into the practice of nursing (American Association of Colleges of Nursing, 2008). Gaul (1987) further stated that development of ethical reasoning abilities and experience with making ethical decisions throughout the baccalaureate educational experience should enable new nurses to experience increased confidence and accuracy in management of clinical situations where ethical implications are present. 


\section{Process to Accomplish}

The purpose of this research was to correlate the knowledge of the Code of Ethics for Nurses of graduating nursing students to choices of action in a clinical situation in order to guide the educational process of nursing students. The research process included exploration of individual characteristics that potentially contributed to the relationship of the students' knowledge of the Code of Ethics and choice of action.

\section{Participants}

The population studied was senior nursing students in baccalaureate nursing programs enrolled in the last semester of classes before graduating. The sample was obtained from several colleges of nursing throughout a state located in the Midwest. These students varied in gender, age, previous life experiences, and coursework not related to their nursing curriculum. Participants were recruited from a class that is required of all graduating seniors at each of the colleges.

The participants were a convenience sample of senior nursing students enrolled in nursing programs at several colleges in a state in the Midwest region of the United States; specifically, nursing students who were in their last semester and planning to graduate at the end of that semester. Each of the colleges graduates students twice a year in the fall and the spring. One of the colleges consists of two campuses with approximately 30 students graduating per campus.

A goal of 200 participants was established. This number met the parameters for a confidence interval of $90 \%$. A $95 \%$ confidence interval seemed unrealistic to achieve since the window of time available to collect data was in the fall and Colleges of Nursing often graduate fewer students in December than in May. All of the data were collected 
from the graduates in the fall semester. The possibility of limited representation is a risk for this study. Methodology

This was a quantitative and descriptive research study that utilized an established instrument to survey nursing students. Surveys examine relationships between variables and can also assess attitudes, beliefs, preferences, and opinions. Leedy and Ormrod (2013) defined survey research as a method that acquires information about a group of people. The information collected can include opinions, characteristics, attitudes, or previous experiences. When conducting survey research, the researcher asks questions and then tabulates the answers the participants provided. Survey research is descriptive in nature and inferences may be drawn about a population based on the results of the sample. The method of data collection through the use of a questionnaire is considered survey research. Descriptive statistics were used to describe the ethical reasoning ability of the participants. Salkind (2012) stated that the purpose of descriptive statistics is to describe the current status of certain events, and then relate the data to other factors. Analysis of the data collected included measures of central tendency: mean, median, and mode. This allowed comparison of the knowledge the participants possessed of the nursing Code of Ethics.

The instrument used in this study was originally developed over 40 years ago and consisted of a series of six patient care vignettes with moral or ethical implications present in each scenario. It was known as Ketefian's Judgments About Nursing Decisions (JAND) and was divided into two parts; in part A, the participant answered regarding what the nurse should do, and in part B, the participant answered regarding how likely 
the nurse was to follow through with the action identified. (Ketefian, 1981; Ketefian, 1982).

At the time it was developed, the stories in the JAND were hypothetical but drawn from a pool of stories provided by practicing nurses. After the stories were constructed, additional practicing nurses discussed the dilemmas and generated the actions assigned as a response to each situation. Following this step, eight nationally recognized nurses rated each story on the degree each nursing action reflected ethical nursing behavior as defined by the Code of Ethics for Nurses thus providing content and face validity. A pilot test of the tool conducted at that time on 63 nurses demonstrated an internal consistency test using coefficient alpha of 0.70 . This data was obtained before the initial use of the instrument (Ketefian, 1982). The tool was used first by the developer (Ketefian, 1981; Ketefian) but it has since been used in additional studies (Gaul, 1987; Turner, 1990; Turner \& Bechtel, 1998) supporting the validity and reliability.

The current version of the JAND used in this study consisted of eight patient care vignettes with moral or ethical implications present in each story. Each vignette was followed by a series of nursing actions. Aligned with each nursing action were two columns. In column one, using a Likert type scale, the participant answered regarding what the nurse should do. Then in column two, again using a Likert type scale, the participant decided how likely the nurse was to follow through with the action identified. The numerical average of all responses for each column becomes the score. Strongly agree $=5 ;$ agree $=4 ;$ neutral $=3 ;$ disagree $=2 ;$ strongly disagree $=1$. This is done separately for column A and for Column B. Thus, there will be separate scores for each item for the 
entire sample, reflecting the sample means for column A and for column B (S. Ketefian, personal communication, December 2, 2012).

The newer version of the JAND was based on the 2001 edition of the Code for Nurses according to the American Nurses Association, and included updates in the stories and the nursing actions. This version better reflected the evolving nature of nursing practice within the societal context and allowed respondents to rate each nursing action using a Likert type scale. A number of items were included that are characterized as ambiguous, meaning that it is hard to find clear evidence in the Code of Ethics whether such action is a good or poor choice. An example of ambiguous activity is where a nurse would report a medication error by calling a relevant party to report the error without identifying herself or himself. Reporting these errors is an appropriate action, but not identifying oneself and providing more relevant information shows lack of accountability and follow-through (S. Ketefian, personal communication, December 2, 2012).

According to S. Ketefian (personal communication, December 2, 2012), this instrument was administered to 30 nurses from acute care settings. Reliability scores were computed for this sample of 30 nurses. Coefficient alpha was used, yielding .71 for column A (26 usable cases) and .78 for column B (27 usable cases). In addition, the scores for the two columns were compared using a $t$-test for non-independent samples, resulting in a $t$ value of $4.403, d f=29, p=.000$. Following the administration of the test to the above sample, revisions were made in the instrument to achieve greater clarity among the nursing actions and the October 2007 version of the JAND was developed at that time. This version is similar but not exactly the same as the version on which the above 
results were obtained (S. Ketefian, personal communication, December 2, 2012). The October 2007 version was used in this study.

Procedure

Data collection was done by the researcher with the cooperation of the colleges and its faculty members. The researcher approached the administration of each participating college and received permission to approach the faculty of the school. Then the researcher obtained permission from the lead faculty member for a senior course to schedule a meeting with the students during class time and administer the questionnaires. The colleges participating in the study are located in the central and western part of a state in the Midwest. The researcher traveled to the separate campuses to attend the class that all seniors are required to complete just before they graduate, and administered the instruments used to collect the data.

The researcher received Institutional Review Board (IRB) approval from the educational organization overseeing the research process and also complied with the policies and procedures at each facility that directed the process of working with human subjects. All participants provided voluntary and informed consent. The participants did not need to identify themselves on the survey form, so anonymity was preserved. The diversity of the students who comprised the sample prevented identification by any of the variables. The demographic variables identified were age, gender, other academic degrees held, previous experience with ethical situations and additional college credit earned in ethics courses. When the questionnaire was administered, this data and other demographic information about the participants were collected using a separate information sheet. The participants were asked to provide some personal information and 
to complete the questionnaire consisting of patient care vignettes with moral or ethical implications present in each scenario; consequently, the risk to the participants was minimal.

Research Question 1

What is the relationship between knowledge of the Code of Ethics and choice of action in given scenarios by senior baccalaureate nursing students?

In order to answer this question the participants completed the Judgments about Nursing Decisions (JAND). Using descriptive statistics, the researcher determined the mean for each response for each action in column A and Column B. After that, correlational statistics were used to determine the relationship between the actions a nurse should take and the likelihood that the nurse would realistically implement the action. Conversely, correlational statistics were used to determine the relationship between the actions not recommended and the likelihood that the nurse would realistically implement the action. Comparison of the mean for each action to the likelihood of implementation of that action illustrated the strength of the relationship between the action and implementation of the action. For example, did the subject recognize whether or not the action was recommended and indicate that the likelihood of taking the action was consistent with what they knew to be correct and appropriate.

Research Question 2

What impact does previous coursework on ethical content have on the relationship between knowledge of the Code of Ethics and choice of action in given scenarios? 
In addition to administering the JAND, this researcher used a separate information sheet to collect details that identified demographic information and additional characteristics which potentially contributed to the ability of the nursing students to reason ethically. One question asked how much college credit in coursework containing ethical content each participant had earned. Descriptive statistics were used to determine a mean value. Using the mean, the participants were divided into two groups; Group 1 participants had earned college credit that exceeded the mean, Group 2 had earned college credit that averaged less the mean. Participants whose earned college credits in courses with ethical content were equivalent to the mean were not used in the comparison. The relationship between the action and the likelihood that the action would be implemented appropriately was determined separately for each subgroup through the use of correlational statistics. The correlational coefficients were then compared in order to determine if additional coursework in ethics influenced the relationship between knowledge of an action and the likelihood that the action would be implemented. Research Question 3

What impact does previous clinical experience with ethical situations have on the relationship between knowledge of the Code of Ethics and choice of action in give scenarios?

In addition to administering the JAND, this researcher used a separate information sheet to collect details that identified demographic information and additional characteristics which potentially contributed to the ability of the nursing students to reason ethically. One question asked each participant to indicate if he or she had ever had to make important or critical decisions about the health care of another individual. Using 
the categories of yes or no, the participants were divided into two groups. Group 1 had been involved in making decisions about the health care of another individual; Group 2 had not been involved in making decisions about the health care of another individual. The relationship between the action and the likelihood that the action would be implemented appropriately was determined separately for each subgroup through the use of correlational statistics. The correlational coefficients were then compared in order to determine if previous experience influenced the relationship between knowledge of an action and the likelihood that the action would be implemented.

\section{Additional Variables}

In addition to collecting data on the level of experience and education of the participants, the separate information sheet also identified the age, gender, ethnicity and religious preferences of the students who completed the survey. These data were used to describe the characteristics of the sample population. The separation and formation of groups according to the quantity of education on ethics or previous experience with ethical situations allowed the option of reporting the data across the groups to determine the influence of these variables on knowledge and choice of action.

\section{Summary}

Whether or not nursing students are adequately prepared to make ethical decisions at the time of graduation is not clear (Dierckx de Casterlé, et. al., 1997; Krawczyk, 1997; Nolan \& Markert, 2002). The purpose of this research was to correlate the knowledge of the Code of Ethics for Nurses of graduating nursing students to choices of action in a clinical situation and included exploration of individual characteristics that could potentially contribute to the students' knowledge and choice of action. This study 
explored how knowing related to action. Specifically, what knowledge did senior baccalaureate students possess on the Code of Ethics for Nurses and how did that knowledge correlate to action in specific scenarios.

The instrument used was the Judgment About Nursing Decisions (JAND). This instrument was a questionnaire which consisted of eight patient care vignettes with moral or ethical implications present in each story. Each vignette was followed by a series of nursing actions. Aligned with each nursing action were two columns: in column one, using a Likert type scale, the participant answered regarding what the nurse should do, and in column two, again using a Likert type scale, the participant decided how likely the nurse was to follow through with the action identified. Also used was an information sheet to collect additional demographic data about the participants to determine if individual characteristics influenced the knowledge and understanding of the student. In the following chapter, the available literature including prior research on ethical knowledge and ethical actions in nursing are summarized. 


\section{CHAPTER II}

\section{REVIEW OF THE LITERATURE}

Introduction

In the today's complex health care environment, nurses must to be able to provide ethical care to patients with complex needs. Providing this level of care is timeconsuming and can be challenging. Often the healthcare needs of the patients require that nurses assist them in making choices of treatments that influence outcomes; many times these choices require reflection on the ethical implications of each option. Ethical competence is the ability to recognize when situations are ethical in nature, identify different potential solutions, and then take action. Ethical knowledge or even the ability to reason in an ethical manner would not be necessary if only one right solution existed for every dilemma and that solution was easy to implement (Ulrich, 2012).

In addition to being an expectation of professional behavior; honesty and ethical practice reflect the value of integrity. Integrity, the ability to practice according to established standards of care, is seen when the nurse is honest with his or her patients regarding treatment options (American Association of Colleges of Nursing, 2008). Nurses make decisions in practice that could potentially create value conflicts for their patients. Decisions regarding patient care made from the nurse's priorities instead of the patient's may result in undesirable outcomes (Weis \& Shank, 2000). The professional nurse must maintain balance between evidence-based knowledge, skills and attitudes as well as confidence, caring and compassion. Altruism, a concern for the well-being of 
others is another professional value. An altruistic nurse demonstrates concern and advocacy for his or her patients (American Association of Colleges of Nursing). Without these abilities and characteristics, decisions regarding patient care may be made from the nurse's priority instead of the patient. This review of the literature will address: an overview of the theory of ethics, a description of ethics in nursing, the role of ethics in nursing practice, an overview of educational methods, and the impact of education on ability to reason ethically.

\section{Theory}

Ethics is a general term referring to a sub-theory of the subject of philosophy that is primarily concerned with understanding moral attributes of life and what is good or right (Gibson, 1993; Scanlon, 1995). Ethics is further subdivided into additional categories. Utilitarianism defines an action as right when it provides the greatest benefit to the majority of those who are affected by the consequences of the action. According to utilitarian theory, people act in a manner that promotes the greatest well-being for the greatest number of people. Deontology focuses on the actions of the individual. The action is either good or bad, never in between, and is referred to as an obligatory duty (Tännsjö, 2012).

Nursing ethics is inclusive of the norms, values, and principles that guide the decisions and actions of those who practice within the profession (Scanlon, 1995). Juujärvi, Pesso, and Myyry (2010) discussed the differences between the ethic of care and the ethic of justice. Both are aligned with the deontological framework. The ethic of justice is focused on maintaining obligation, equity, and fairness through application of moral principles and rules. In justice ethics, reasoning by a hierarchy of rights and rules is 
used to resolve moral conflicts by weighing contradictory and individual claims. The ethic of justice focuses more on individual rights while the ethic of care addresses responsibilities in relationships. Care ethics is an approach that facilitates analysis of moral behavior and approaches the behavior from the context of specific care relationships (Vanlaere \& Gastmans, 2011).

Virtue ethics focus on the moral character or virtues of the individual. The premise of virtue ethics is that certain qualities are desirable and possession of them results in a person being virtuous or good; virtuous people perform good actions. In other words, the formation of the person's character influences his or her conduct. Character traits can be developed, while personality traits are believed to be determined by biology (Smith \& Godfrey, 2002; Tännsjö, 2012). The basis for virtue ethics is that the individual wants to know and do good work. As a result, virtue ethics is consistent with the context of nursing practice i.e. virtue is acquired, not inherited and that virtue ethics directly connects with the concept of a good nurse who practices good nursing (Smith \& Godfrey). Bishop and Scudder (1996) refer to ethical nursing as the level of care that exists when a good nurse does the right thing. Good nursing care implies a responsive attitude from the nurse; a nurse who is attentive to how the care is received and the impact it brings to the patient and family (Dierckx de Casterlé et. al., 2011).

With care reasoning, sensitivity to the unique attributes of persons and situations are bound to judgments of responsibility (Goethals, et al., 2010). Using the perspective of care ethics allows one to closely examine how the responsibilities of care take place and be inclusive of the characteristics and context of the situation, interaction of the players involved, and the emotions present (Vanlaere \& Gastmans, 2011). In nursing, the 
dominant theory found in stories of everyday practice is one of care and responsibility with care defined as the alleviation of vulnerability (Benner, 1991). Consequently, the public consistently rates nurses as high in honesty and ethical standards (Jones, 2010).

An ethical dilemma is a situation where conflict exists between the values or choices of action and arguments can be made for either position (Cooper, 2004; Gibson, 1993). Although ethical dilemmas have been a part of nursing care since nursing began, it is particularly relevant in today's health environment. Health care professionals, especially nurses, address life and death situations when providing care for their patients. People, when they are patients, trust their lives and general health to the nurses that are responsible for their care. An ethical dimension of care is essential and encompasses all aspects of nursing care, not just the beginning and end of life (Bishop \& Scudder, 1990, Vanlaere \& Gastmans, 2011).

Beginners or novices without experience use rules to guide them in making decisions. Discretionary judgment is the ability to use rules to guide behavior and decisions that are unrelated to the context of the situation. As novices, nurses frequently lack the ability to use discretionary judgment (Benner, 1982). Whether or not nursing students are adequately prepared to make ethical decisions at the time of graduation is not clear (Dierckx de Casterlé, et al., 1997; Krawczyk, 1997; Nolan \& Markert, 2002). However, students need opportunities to address and effectively manage ethical situations while they are students to ensure they can manage them as professionals. In order for nursing students to be prepared to practice effectively in clinical situations where ethical implications exist, the education process needs to be effective (Cameron, et al., 2001). 
Benner, Sutphen, and Leonard-Khan (2008) stated that simply reducing the process of ethical practice to standards of care does not provide a strong agenda for developing ethical comportment, also described as presence, in the practitioner. Ethical competence is more than recognizing situations with ethical implications; it also requires the ability to take action. Thus, ethical practice can be challenging because nurses still work closely with physicians and often implement the medical plan. The complexity of health care environments can lead to conflicts in values; consequently, nurses often state that they have difficulty implementing the ethical dimension of their practice. When this occurs the nurses experience moral distress and a sense of powerlessness (Goethals, et al., 2010; Ulrich et. al. 2010).

\section{Description of Ethics in Nursing}

Ethics and ethical dilemmas are not new to nursing. The ANA (American Nurses Association) adopted the first official code of ethics in 1950. Prior to that time, the Florence Nightingale Pledge, written in 1893, was considered to be the first code of ethics in nursing. Between 1893 and 1950, nursing professionals made several attempts to create a standard of practice with respect to ethics, but were not able to reach consensus. However, once the first code was adopted in 1950, focus shifted to enforcement of the principles contained within it. The next revisions occurred in 1968, 1985, and most recently in 2005. Each revision addressed the importance of the nurse adhering to the standards of the profession (Fowler, 2008).

Since nursing practice is guided by a Code of Ethics the climate in the patient care arena has influenced the implementation of ethics education for nurses (Bosek \& Savage, 2007; Fowler, 2008; Wehrwein, 1996). In ethically charged situations, nurses are 
responsible for protecting their patients and serving as advocates for them. When acting as an advocate for a patient, integrity is an important characteristic of the nurse. Nurses of integrity integrate personal and professional values to protect a person who is vulnerable and are trusted by their patients to do just that (Ulrich, 2012).

While nursing is facing continuous challenges in the nature of the ethical circumstances in practice, Scanlon (1995) pointed out that nursing has encountered professional issues and ethical questions throughout its history. Examples included issues of consent, refusal of treatment, the patient's right to die and whether or not to override the physician by answering a patient's questions truthfully. Technology and new developments in treatment options have resulted in more conflicts between value systems of both nurses and their patients (Aroskar, 1977). Nursing traditions are laden with moral ideals and a commitment to the well-being of the patients for who care is provided. An interest in the study of ethics has evolved with the growth and changes in the practice of nursing over the last several years (Fowler \& Tschudin, 2006).

Benner (1991) defined nursing practice as a set of skilled actions that have a notion of good embedded in them. Experience was gained when one learned to recognize ethical distinctions in practice with specific patients and their families. Experience teaches the proficient nurse what typical events to expect and how to modify plans in response to these events (Benner, 1982). Candela and Bowles (2008) emphasized the dichotomy that exists between practice and education. Entering the workforce as a new nurse can be overwhelming and employers continue to affirm that graduates do not seem ready for the workplace. While ethics is not a science with verifiable answers, an understanding of ethical theory enables a nurse to practice in a comprehensive manner 
(Gibson, 1993). Dierckx de Casterlé, et al. (1997) declared that nursing practice is ethical when reasoning and implementation of action are both present and ethical.

Over the last few decades, in order to facilitate reflection on human selfunderstanding, the emphasis on care has become increasingly important. This has resulted in the connection of the concept of care to the ethical theory in practice (Vanlaere \& Gastmans, 2011). The complexity of health care and the technology available for treatment options predisposes nurses to dilemmas when providing care for patients. An ethical issue may arise in any clinical situation (Ulrich et. al., 2010). The relationship established, the patient, and the individual professional experiences of each nurse may result in different perspectives and approaches when ethical issues are confronted in practice. Issues which were private in the past are now more public in nature; consequently, outcomes may be influenced by sources outside of the nurse-patient relationship such as through the court system and legislation (Scanlon, 1995).

Nurses who are capable of reasoning at a high moral or ethical level are assumed to be more likely to make decisions that reflect value and respect for their patients. Educational institutions are responsible to ensure that nurses and nursing students be capable of thinking ethically thus placing responsibility on educational institutions to prepare students to meet these demands (Felton \& Parsons, 1987; Hsu \& Hsieh, 2009; Hunink, et al., 2009; Mustapha \& Seybert, 1989; Scanlon, 1995). As a therapeutic discipline that exhibits the attributes of caring and nurturing, ethics is a natural component of the profession. However, nursing is more than rules and regulations. Nurses build therapeutic, interpersonal relationships that are caring in order to support and empower their patients and their patient's families (Lemonidou, et al., 2004). 
Often the magnitude and complexity of the legal and ethical issues exceeded the regulation available through the Codes of Ethics (Turner \& Bechtel, 1998). Each time the Code of Ethics was revised, the adjustments reflected changes in the health care environment including autonomy of the nursing role, access to health care as a right of all, increased focus on global influences in health, a patient's level of involvement in his or her own care, and ultimately the relationship between the personal and professional ethics of a nurse. The current Code of Ethics is fluid in use of terminology, allowing accommodation of changes in practice settings and new venues of nursing without requiring revision (Fowler, 2008).

\section{Role of Ethics in Nursing Practice}

According to Bosek and Savage (2007), clinical ethics in nursing represents application of the use of ethics in practice. It involves the actions and decisions made by clinicians, such as nurses, regarding care of a client. The ability to communicate the emotion of caring while in the process of providing physical care for patients is a critical component of maintaining an ethical practice. Ethical practice is based on specific rights of the patient constructed from the principles of autonomy, beneficence, nonmalfeasance, truth telling, fair allocation of scarce resources, and a general sense of fairness (Benner, et al., 2008; Bosek \& Savage). Poikkeus, Numminen, Suhonen, and Leino-Kilpi (2013) determined the need to develop evidence-based support at both the organizational and the individual level in order to support the ethical competence of nurses. Nurses use ethical reasoning in all aspects of their practice and are a profession that is highly respected by the public (Bosek \& Savage; Dierckx de Casterlé, et al., 2008; Jones, 2010; Scanlon, 1995; Ulrich, 2012). Professional values are standards of practice 
for practitioners of professional groups that provide a framework for evaluating behavior (Weis \& Shank, 2000). Preparing students to use ethical reasoning and be able to practice with integrity is a required component of nursing education. The Essential most aligned with the professional aspect of practice is Essential VIII-Professionalism and Professional Values (American Association of Colleges of Nursing, 2008).

Included in the rationale for Essential VIII is a statement stressing that baccalaureate nursing graduates be prepared to respond to numerous dilemmas and to make decisions about patient care within an ethical framework. Understanding the values that are brought to the relationship by each patient and anyone else involved in patient care is crucial to the quality of care and is evidence of the professional value of autonomy (American Association of Colleges of Nursing, 2008). Weis and Shank (2000) reinforced that understanding of the patient's values is crucial to effectiveness when responding to ethical dilemmas. Decisions about practice and treatment can potentially create value conflicts and result in clinical situations with ethical questions.

At the beginning of nursing practice, nurses were expected to be loyal to the physician. As consumers became more informed, patients were expected to be included in planning treatments (Bosek \& Savage, 2007; Gaul, 1987). In the health care environment today, nurses are often part of a multidisciplinary team and work in environments that change quickly. Thus, while nursing requires a great deal of technical knowledge, nursing practice also requires strong communication skills. To be ethical in practice requires one to have mastery of communication skills. Implementing ethical care requires confidence and moral courage where the nurse operates from his or her moral 
compass and takes action to implement the right care at the right time even if the action is not a popular one (Gaul, 1987; Ulrich, 2012).

This trust placed on nurses requires that they carry out all responsibilities without the influence of their personal beliefs and values (Dinç \& Görgülü, 2002; Nolan \& Markert, 2002). Arman and Rehnsfeldt (2007) described how caring theory is directly related to ethical care. When a nurse approaches a patient from the patient's belief structure, he or she is providing care that is ethical. It is the emphasis on the patient and his or her welfare that helps to convert caring into ethical care. Ideal caring involves crossing into private areas; doing what is necessary to assist the patient, not staying within the rules and boundaries simply to be compliant with them. However, when nurses face significant conflicts between their personal values and the patient's values, the nurses can experience moral distress resulting in a negative impact on both patient and nurse (Goethals, et al., 2010). Ethical practice reflects professional values and clients expect professional nurses to behave in a consistent manner (Hsu \& Hsieh, 2009; Paulsen, 2011).

Bishop and Scudder (1990) defined nursing as a moral practice that places the importance of promoting the well-being of the patient by caring for him or her through the establishment of a personal relationship. Gastmans, Dierckx de Casterlé, and Schotsman (1998) described a fundamental view of nursing care as a moral practice utilizing three components: the caring relationship, caring behavior as an integration of virtue and expertise, and the ultimate goal of nursing practice which is good care. In order to be applied consistently a standard needs to be established determining what is good or desirable (Smith \& Godfrey, 2002). While the concept of good care is consistent 
with application to practice, many nurses have adopted the premise that it entails more than physical tasks.

Nursing practice today is challenging. Increased patient acuity, proliferation of technology, and decreased length of hospitalization stays place increased demands on nurses (Benner, 1982). Nurses frequently encounter difficult clinical situations daily. Examples include assisting patients in making challenging decisions about their care or the care of a family member. The decision-making process may be inclusive of the patient, family, and other health-care team members, requiring analytical, critical, reflective attitudes. Hunink, et al. (2009) stated that the characteristics of nursing practice indicate that moral development of nursing students is significant in nursing education and reinforced that nurses are expected to be actively involved in ethical decision-making regardless of the practice setting.

\section{Overview of Educational Methods}

Many clinical situations have ethical considerations that influence the choice of outcomes or solutions; often there is not a single solution appropriate for all clients (Lemonidou, et al., 2004). To be able to practice as a professional nurse requires the ability to make ethical decisions and to carry out the actions necessary to implement the patient choices (Dinç \& Görgülü, 2002). Wehrwein (1996) addressed the concern that nurses do not have difficulty recognizing and assessing an ethical dilemma in practice; instead, they may struggle with the ability to implement the plan. They may not be empowered to act on the choices expressed by the patient.

Education in ethics and ethical theory provides the nurse with tools to reflect critically on the care they provide in their practice (Vanlaere \& Gastmans, 2007). 
Educators in nursing curriculums are challenged to prepare students to practice in the complex health care environment. Since the work of nursing impacts lives, it is imperative that students are educated and socialized to make ethical decisions (Turner \& Bechtel, 1998). The intent of ethics education of nursing students is to develop skilled practitioners capable of detecting and responding to the ethical issues faced by nurses in practice. Active participation by the student facilitates this process (Görgülü \& Dinç, 2007).

Using a tool known as The Nursing Dilemma Test, Ham (2004) conducted a descriptive study comparing the ethical reasoning abilities of senior baccalaureate nursing students and experienced nurses. Particularly, she was interested in how environmental factors, practical considerations, and experience with previous ethical dilemmas influenced the ethical decision making process in nurses. An example of a practical consideration is fear of a lawsuit or the anger of a physician. Rational decisions that are ethical in nature may be multi-faceted, aligning with the standards of practice in addition to the patient's preferences. Principled thinking was defined as the level of moral reasoning that is reflective of stage five or six in Kohlberg's model of moral development (Ham). The questionnaires were scored to measure the principled level of thinking in each group and the results indicated a significant difference in the form of a higher mean score for nursing principled thinking in the nursing students indicating that as registered nurses gained more experience their use of principled thinking decreased (Ham).

Nurses need to be ready and able to challenge outdated practices, analyze the situation, and then justify clinical actions; what Holt and Long (1999) call knowledgeable doers. Knowledgeable doers will act on their moral compass instead of blindly 
implementing the status quo or following the direction of another individual (Holt \& Long, 1999; Ulrich, 2012). Arman and Rehnsfeldt (2007) used a qualitative, hermeneutic methodology consisting of two Socratic dialogues with registered nurses, nursing students, and former patients to investigate the substance of ideal care and to identify clinical indications of good ethical care. They initiated this study to examine the clinical evidence of nurse-patient encounters that served to reduce patient suffering.

An assumption embedded in the research process was that ethical and existential features are vital in health care. Through the research process Arman and Rehnsfeldt (2007) identified three themes that were dependent on the role of the participant. The participants were nurses, nursing students, and patients. According to the nurses, ideal caring meant responding to the whole person, delivering care with respect. The nursing students indicated that ideal caring meant acknowledging unique circumstances of the patient's situation and planning care accordingly. Ideal caring, as represented by the patients, was demonstrated through genuine interest and commitment to the patient as a person, not a diagnosis.

Iglesias, et al. (2011) conducted a study where the authors utilized journaling in order to evaluate nursing students' understanding and attitudes about bioethical dilemmas. Students were asked about their knowledge of and position regarding: eugenics, experimentation with non-implanted embryos, human cloning, abortion, and euthanasia. The results of this study indicated that the students took a stronger position on the biomedical issue, positive or negative, when they had a high degree of familiarity of the topic. However, the students expressed a neutral stance on the issues most unfamiliar 
to them. Iglesias, et al. described the risk that failure to understand and take a position on any issue may result in inappropriate or inadequate care for the patient.

Reflection and journaling have been used frequently to introduce the concepts of ethical reasoning and moral behavior to students. Turner and Bechtel (1998) utilized guided design as an instructional method of ethical decision making in community health nursing students. After the introduction of the guided design, they used Ketefian's JAND to evaluate the processes of ethical decision making and moral reasoning in these students. While no differences were identified in the ability of the students to use moral reasoning, Turner and Bechtel identified a significant difference in the ethical decision scores between the pre-test and the post-test that reflected the ability of the students to make ethical decisions and supported the use of guided design as an instructional method.

Durgahee (1997) defined reflection as a critical analysis of experience and over a five year period of time had students who were enrolled in a palliative care course use diaries and stories to relive clinical experiences where ethical implications were present. Based on the results of this research, Durgahee concluded that self-concept, communication skills, and the development of insight were influenced due to the catharsis of reflection. Nursing students need opportunities that promote development in moral and ethical reasoning. These experiences facilitate the development of nurses to practice within the framework of the American Nurses Association Code of Ethics (Wehrwein, 1990).

Beckett,et al. (2007) analyzed reflective essays written by second year nursing students. The purpose was to examine the students' understanding of their clinical experiences. The students' essays highlighted their ability to consider patient care from a 
holistic perspective, communicated a preoccupation with a perceived lack of skills and knowledge, and clearly demonstrated the ability to negotiate complex relational ethics. Only some of these students had taken a nursing ethics course.

Because the students were novices, the staff and educators assumed a lack of clinical knowledge. Yet through journal analysis, Beckett, et al. (2007) identified that while students expressed feelings of inadequacy in skills and knowledge, they actually possessed advanced relational skills facilitating their ability to negotiate complex situations in highly effective ways. Implications from this study illustrate that nurse educators need to increase their awareness of the students' ability to evaluate and respond to ethical situations in the clinical setting (Beckett, et al.).

Callister, et al. (2009) also used reflective journaling to describe and analyze the ethical reasoning ability of 70 baccalaureate nursing students. All of the students were enrolled in both a nursing ethics course and a maternal-child nursing course. The clinical experiences of the students from the maternal-child course were captured in reflective journals. The students wrote their journals using a standardized format. Throughout the journaling process, the students demonstrated a high level of critical thinking and a deep commitment to ethical nursing practice. After reviewing the journals, the authors identified a primary theme they called "in the process of becoming" (Callister et al., p. 502). The learning articulated by the students reflected progress toward becoming a nurse committed to ethical clinical practice.

Much of what the students shared in their journals indicated an understanding of ethical reasoning and behavior but not mastery of these skills. Callister, et al. (2009) identified the students' ability to make ethically sound decisions as a process and offered 
several implications for nursing education. Additionally, they predicted that the results of this study would assist educators in becoming more effective in designing educational experiences for students and expressed hope that more effective preparation of nursing students would result in stronger ethical reasoning in licensed professional nurses.

Callister, Ravert, Stoneman, and Matsuma (2004) reviewed reflective journals of senior nursing student and identified three themes. The first theme illustrated an integration of ethics in both personal and professional life. The students articulated a clear link between their personal and professional lives; they verbalized that they would have difficulty separating the two segments, especially after what they had experienced clinically. The second theme showed a strengthened commitment to professional integrity. After observing clinical situations where the student felt that care had been compromised or not aligned with the patient's wishes, many of the students verbalized the belief that they would not practice in any manner that would be less than honorable. Thirdly, the students exhibited a theme of empowered caring and included behaviors like speaking up, taking a stand, or refusing to participate. This theme was described as an integration of the ethics of care with the ethics of justice.

Anonymized reflection is the process of clarifying new experiences with intent to develop new insight from small group interaction and reasoned argument in order to enhance ethical decision. Kyle (2008) used anonymized reflection to determine the effectiveness of instruction of ethical content to nursing students in a baccalaureate program. The students found the learning meaningful and indicated a preference for this style of instruction. Nolan and Markert (2002) conducted a longitudinal study to explore the ethical understanding of nursing students as well as the changes and growth that 
occurred over the course of their training. Throughout the study the students demonstrated maturity and progress in their thinking, but while they valued the course on ethics, they did not consider their clinical experiences influential on their ability to reflect on ethical circumstances.

Taking a different approach, Baxter and Boblin (2007) explored the concept of unethical behavior in nursing students. After describing examples of unethical behavior, Baxter and Boblin used the theories of Kohlberg, Gilligan, and Rest to explain the actions of the students and suggested several strategies that nurse educators could consider useful to promote moral development in students. Faculty members were encouraged to create a positive environment where students could freely ask questions, solve problems, and admit mistakes if they had been made. In addition, Baxter and Boblin identified that faculty need to be aware of their own practice and conscientiously model ethical behaviors for their students.

Landry and Landry (2002) oversaw a year-long project designed to integrate an ethical-legal course and a medical-surgical nursing course for the purpose of having students participate in an interactive learning experience involving ethical-legal issues. Through the design of this project, the authors piloted a different methodology for instruction of ethics to nursing students. They wanted to provide meaning to the ethicallegal content by putting it into context and relating it to practice. The students took these courses during the first semester of their junior year. Landry and Landry reviewed how technology, economics, and health care reform contributed to difficulty in understanding the relationship between practice and ethical-legal concepts. They also identified the complexity of ethical-legal concepts as intricate and challenging to novice nurses. The 
implications drawn from the results of this study supported the idea that nursing students will benefit from enhanced learning when core courses are linked with a course exploring ethical-legal content.

Krawczyk (1997) compared the moral development of freshman nursing students to senior nursing students at three separate baccalaureate nursing programs that differed in how ethical content was incorporated into the curriculum. Program A incorporated a three hour course on ethics, program B integrated ethical content and issues throughout all nursing courses, and program $\mathrm{C}$ did not include any content on ethics into the curriculum. As a result of the study, Krawczyk concluded that the content and instructional format of ethics courses is important. Educators have used different strategies to teach ethics and ethical sensitivity but these strategies have not been consistently supported as effective by research; often they are merely an indication of the interest of faculty members (Krawczyk; Nolan \& Markert, 2002). Yet, through the research process, Krawczyk determined that the students who had completed more time in a class setting on the study of ethics scored higher on tests designed to measure moral judgment. Krawczyk did not determine if it was the content of the course or the format that led to the increased ability of the students. Designing courses clearly related to nursing practice and finding time in a curriculum to discuss and explore issues relevant to practice is difficult. Plus there is little literature to guide the educator regarding effective methods to teach ethical content in order to develop ethical reasoning in nursing students (Nolan \& Markert).

This lack of support in the literature exists partially because of a discrepancy regarding what is meant by the concept of ethical sensitivity. Some disciplines used the 
term ethical sensitivity interchangeably with other terms; examples of these terms are moral sensitivity, clinical sensitivity, ethical perception, ethical intuition, and moral sensibility. Weaver (2007) described ethical sensitivity as a prerequisite to determining if ethical implications are present in a care situation and further discussed how it has been defined by a variety of professional disciplines such as nursing, medicine, dentistry, philosophy, and business.

Weaver and Morse (2006) defined ethical sensitivity as the means and capacity that professionals exhibit when they recognize and respond compassionately to those in their care. Through methodical analysis of the literature of nursing and related professions, Weaver, Morse, and Mitcham (2008) clarified the concept of ethical sensitivity and established a common understanding of the terminology. The researchers established a common understanding of the terminology, recognition of attributes, relationships of each term to other terms, and clustering of the components. The definition included the key characteristics of moral perception, affectivity, and dividing loyalties. Acceptance of ethical sensitivity as it relates to other terms, without defining it specifically, impacts understanding and application of the concept in a clinical setting. Clarification of ethical sensitivity as a concept enhanced the ability of professional nurses to recognize and communicate about the ethical dimension of their work (Weaver, et al.).

Through qualitative analysis of many descriptors found in the literature, Weaver (2007) elaborated and improved comprehension of the concept ethical sensitivity. She described ethical sensitivity as a mental representation of a phenomenon; a word that represents a concept. Weaver further explained that ethical sensitivity is a behavioral concept that has several meanings in the literature; that there was not a consensus on the 
definition. In subsequent research, Weaver used an exploratory design to conduct a content analysis of 200 books and articles and described ethical sensitivity as an emerging, low level scientific concept that is representative of an aspect of decision making in professional practice.

Dierckx de Casterlé, et al. (1997) used an instrument based on Kohlberg's theory of moral development to study the ethical behavior of nurses. They defined ethical behavior as behavior based on the nurses' own decisions, personal value judgments, and commitment to promoting patient welfare. After reviewing the data, they then determined that nursing students function at the conventional level of moral development.

Using a version of the Moral Sensitivity Questionnaire adapted to accommodate nursing students and called the Modified Moral Sensitivity Questionnaire for Nursing Students (MMSQ-NS), Comrie (2012) conducted a mixed method designed study in order to explore nursing student perceptions about moral sensitivity. Three levels of students completed the tool; junior baccalaureate students, senior baccalaureate students, and graduate nursing students. After analyzing the data, Comrie concluded that different levels of moral sensitivity existed in the junior, senior, and graduate level students and recommended that nursing education should assist the student to make the transition from student to practicing nurse. When ethical dilemmas are included, analyzing case studies and simulation scenarios are examples of recommended methodologies.

Using quantitative methods to analyze the type and frequency of ethical dilemmas encountered by the students and qualitative methods to evaluate the process of decision making used by the students in response to ethical situations, Han and Ahn (2000) identified specific ethical reasoning capabilities of baccalaureate nursing students. They 
noted that the students were able to identify ethical issues as well as rationally apply principles of ethics in the decisions made to manage the situations. The student abilities were clearly identified, supporting the notion that nursing students do face ethical dilemmas in the clinical setting, and reinforcing the need to know what ethical reasoning abilities graduating baccalaureate nursing students possess.

Anticipating that the results of their study would assist educators in becoming more effective in designing educational experiences for students, Cameron, et al. (2001) asked senior baccalaureate nursing students to explore a situation in their nursing practice that had caused them conflict. The incidents described fit into one of five categories: problems involving health professionals, problems involving quality of life/death and dying, conflict about the right thing to do, management of persons with a contagious disease, and managed care concerns. The students described the conflict and any ethical concerns for the care required by their patients. After identifying the situation, each student included how the conflict was resolved and an explanation about how they applied an ethical decision-making model studied in class. The authors identified the stress the students felt when they could not resolve an ethical situation well and expressed a belief that nursing education should be more effective in the preparation of nursing students in order to produce stronger ethical reasoning abilities in licensed professional nurses.

\section{Impact of Ethics Education}

Fowler and Davis (2013) supported that inconsistency in nomenclature continues to be problematic in addressing ethical issues in nursing education but expanded that inconsistency to include any systematic exploration of ethical issues occurring within the 
nursing educational process stating "In 2008, less than $10 \%$ of the nursing journal articles that were identified actually addressed ethical issues in nursing education per se, rather than matters of curricular concern" (p. 127). Education in ethics and ethical theory provides the nurse with the tools necessary to reflect critically on the care they provide in their practice (Vanlaere \& Gastmans, 2007).

The intent of ethics education of nursing students is to develop skilled practitioners capable of detecting and responding to the ethical issues faced by nurses in practice. Active participation by the student facilitates this process (Görgülü \& Dinç, 2007). However, there is also a scarcity of literature and research available that describes the process of ethical reasoning in nursing students (Callister, et al., 2004; Cameron, et al. 2001; Oddi, Cassidy, \& Fisher, 1995; Ulrich et al., 2010). Despite the scarcity of literature and research available describing the process of ethical reasoning in nursing students; in recent years a renewed interest in ethics education has taken place (Callister, et al.; Ulrich et al.).

The literature also supports the inconsistency of how knowledge of ethics and ethical reasoning is taught throughout the various programs in the country. Nursing curriculums vary in how the ethical reasoning ability of students is developed (Comrie, 2012; Krawczyk, 1997; Nolan \& Markert, 2002). Nursing ethics is taught in many ways, from specialized classes to integration into the curriculum; making it difficult to know to what degree that students can reason ethically. Some nursing programs require an ethics of health care course; others require a generic ethics course that is not specific to nursing or even health care. Other nursing programs embed the content throughout all courses in the curriculum, and some include instruction on ethical principles only if situations are 
encountered during a clinical practicum. (Aroskar, 1977; Dierckx de Casterlé, et al., 1997; Krawczyk; Nolan \& Markert).

Ethics is a deeply personal process embedded in the work of nursing, making the development of pedagogy for student instruction challenging (Doane 2002; Doane, Pauly, Brown, \& McPherson, 2004). Through analysis of reflective journals, Durgahee (1997) concluded that communication skills increased, the students' self-concept was enhanced, and insight into ethical reasoning increased when reflection on lived experiences was encouraged. When they analyzed the reflective journals written by their students, Callister, et al. (2009) identified that the students showed an understanding of ethical reasoning and behavior, but not mastery of these skills.

Iglesias, et al. (2011) implied a deficiency in the nursing curriculum regarding bioethical issues. These authors expressed concern that lack of knowledge would impact the students' practice, and recommended that additional content on ethics be added the curriculum. Poikkeus, et al. (2013) offered several strategies to support ethical competence in nurses. These strategies included education on ethics, forming committees to review ethical scenarios and provide consultation, and conducting clinical rounds that focus on the ethical needs of the situation.

Baxter and Boblin (2007) also recommended three methods or strategies of instruction in order to facilitate development of ethical reasoning in nursing students. First, faculty members should provide a positive learning environment where honesty is valued and students are encouraged to resolve their mistakes. Secondly, nurse educators need to create opportunities for students to work with a variety of health care workers who operate at different levels of moral development. Most importantly, the third strategy 
reinforced that nurse educators serve as role models for students, requiring them to examine their behaviors and ensure they practice consistently according to the code of ethics established, updated, and revised regularly by American Nurses Association (ANA).

Nolan and Markert (2002) indicated that nursing students should be taught that there will be occasions where their personal code of ethics will conflict with practice. Ham (2004) determined that environmental factors such as fear of a lawsuit or anger of a physician influenced the decisions made by nurses. As a result of their analysis of the literature on ethical-decision making in nursing students, Numminen and Leino-Kilpi (2007) described ethical decision-making as a personal and social affair.

In addition to determining that nursing students function at the conventional level, Dierckx de Casterlé, et al. (1997) acknowledged that women scored slightly, but significantly, higher in ethical reasoning than men. They also recognized that a small but positive and complex relationship exists between ethical reasoning and the implementation of ethical decisions; concluding that ethical reasoning might be just one determinant of ethical behavior. Since character is established at a young age and expands with the development of the individual, Smith and Godfrey (2002) suggested that schools of nursing consider how to evaluate the characteristics of applicants to nursing programs and design curriculums with affective components in order to promote a culture that encourages development of ethical competence.

Inadequate exploration of the terminology lead to bias that resulted in unnecessary influence on the professional involved in caring for an individual. It also impacted the role of education. Ultimately, research was conducted that resulted in the 
evolution and development of the definition of the concept of ethical sensitivity (Weaver, 2007). Clarification of ethical sensitivity as a concept enhanced the ability of professional nurses to recognize and communicate about the ethical dimension of their work. The findings by Weaver supported a recommendation of continued study to increase recognition of the concept from a trans-disciplinary perspective. Development of a common understanding of the term and its application to each discipline where it is used should facilitate identification of educational strategies to assist learners to develop skills in the area of ethical sensitivity.

The ability to make decisions that are ethically based is often learned through practice; consequently, students who were fortunate to encounter ethical situations through their clinical practicum would have an advantage over students who did not. As educators, it is important to assist graduating nurses to develop their ability to reason in an ethical manner (Park, et al. 2012). Efforts to promote ethics education in nursing have been intensified in recent years and necessary learning experiences that result in the achievement of desired outcomes related to ethics has been a major concern among nursing programs. There continues to be a need to determine what abilities new nursing graduates have to manage ethical dilemmas when they begin their practice (Comrie, 2012).

Students cannot depend on chance exposure to a clinical situation in order to develop ethical reasoning abilities. Nursing has an obligation to teach ethical decision making. Instruction in the theory of ethics to nursing students, along with exposure to ethical dilemmas in a clinical environment, is necessary to prepare safe and competent practitioners who are able to manage clinical situations with ethical considerations 
(Turner \& Bechtel, 1998). New graduates frequently express feelings that they are not adequately prepared in the areas of ethical practice, leadership and cultural diversity (Dyess \& Sherman, 2009; Ulrich et al., 2010). To be effective as an ethical practitioner, a nurse needs to be able to recognize when an ethical dilemma exists, and possess the confidence to act on the assessment (Gaul, 1987). Gaul utilized the tool Ketefian's JAND to evaluate if a difference in ethical abilities existed between students who had completed a course in nursing ethics and those who had not. The students who took a separate course expressed that they felt it was beneficial even though the differences in scores between the groups were not statistically significant.

Memarian, Salsali, Vanaki, Ahmadi, and Hajizadeh, (2007), explored factors influential to clinical competency in experienced nursing professionals and specifically identified professional commitment, moral and ethical conduct, useful work experience, and adequate facilities as influential in impacting clinical competency that was ethical. This study involved a population of nurses in the country of Iran and related the ethical competency of the nurse in practice to the ability of the nurse to comprehend culture. The more competent the nurse was in practice the better able to he or she was to understand and work within the boundaries of culture. This relationship was then connected to the difference in the quality of the nurse's desired and current practice. This finding was linked to the educational preparation of nurses and included the suggestion that nurses who practiced ethically obtained better outcomes in their practice.

\section{Conclusion}

Ethics is a general term referring to a sub-theory of the subject of philosophy that is primarily concerned with understanding moral attributes of life and what is good or right. Nursing ethics is inclusive of the norms, values, and principles that guide the 
decisions and actions of those who practice within the profession (Gibson, 1993; Scanlon, 1995). Bishop and Scudder (1990) defined nursing as a moral practice that places the importance of promoting the well-being of the patient by caring for him or her through the establishment of a personal relationship. Ethics of justice and care are two theories within the deontological framework of ethics that are aligned with nursing practice (Juujärvi, et al., 2010). Justice ethics focuses on application of moral principles and rules while care ethics stresses relationships. Virtue ethics places emphasis on the moral character of the nurse, recognizing that certain characteristics are desirable in nurses; presence of these traits results in good actions.

Ethical practice in nursing is based on specific rights of the patient constructed from the principles of autonomy, beneficence, non-malfeasance, truth telling, fair allocation of scarce resources, and a general sense of fairness (Benner, et al., 2008; Bosek \& Savage, 2007). Preparing students to use ethical reasoning in order to be able to practice with integrity is a required component of nursing education as described in the Essentials of Baccalaureate Education for Professional Nursing Practice (American Association of Colleges of Nursing, 2008). The ability to respond to ethical dilemmas in practice requires that the nurse recognize the patient's value system. Understanding the values that are brought to the relationship by each patient and anyone else involved in patient care is crucial to the quality of care and is evidence of the professional value of autonomy (American Association of Colleges of Nursing,).

Integrity, the ability to practice according to established standards of care, is seen when the nurse is honest with his or her patients regarding treatment options; an altruistic nurse demonstrates concern and advocacy for his or her patients (American Association 
of Colleges of Nursing, 2008). Without these abilities and characteristics, decisions regarding patient care may be made from the nurse's priority instead of the patient's. Ethics and ethical dilemmas are not new to nursing; however, it was 1950 when nursing adopted the first official code of ethics (Fowler, 2008).

The current Code of Ethics is fluid in use of terminology, allowing accommodation of changes in practice settings and new venues of nursing without requiring revision. As might be expected, each time the Code of Ethics was revised, the adjustments reflected changes in the health care environment including autonomy of the nursing role, access to health care as a right of all, increased focus on global influences in health, a patient's level of involvement in his or her own care, and ultimately the relationship between the personal and professional ethics of a nurse (Fowler, 2008).

Advent of new technologies and methods to treat disease and illness places nurses in ethically challenged patient care situations more frequently than in earlier years resulting in more conflict between the values systems of nurses and patients (Aroskar, 1977; Ulrich et. al., 2010). The ability to communicate the emotion of caring while also providing physical care for patients is a critical component of maintaining an ethical practice (Benner, et al., 2008). Ethical nursing practice requires strong communication skills, knowledge of technology, confidence, and moral courage as often the action which is the most ethical intervention is not the most popular or the easiest to implement.

Nurses need to be ready and able to challenge outdated practices, analyze the situation, and then justify clinical actions; what Holt and Long (1999) called knowledgeable doers. Knowledgeable doers will act on their moral compass instead of blindly implementing the status quo or following the direction of another individual (Holt 
\& Long; Ulrich, 2012). Learning to recognize the ethical component of practice is often the result of experience. Experience teaches the proficient nurse what typical events to expect, how to modify plans in response to these events, and is gained when one learns to recognize ethical distinctions in practice (Benner, 1982).

Whether or not nursing students are adequately prepared to make ethical decisions at the time of graduation is not clear (Dierckx de Casterlé, et al., 1997; Krawczyk, 1997; Nolan \& Markert, 2002). However, it is clear that students need to have opportunities to address and effectively manage ethical situations while they are students to ensure they can manage them as professionals. In order for nursing students to be prepared to practice effectively in clinical situations where ethical implications exist, the education process needs to be effective (Cameron, et al., 2001). Active participation by the student facilitates this process (Görgülü \& Dinç, 2007).

Hunink, et al. (2009) stated that the characteristics of nursing practice indicate that moral development of nursing students is significant in nursing education and reinforced that nurses are expected to be actively involved in ethical decision-making regardless of the practice setting. Nurses who are capable of reasoning at a high moral or ethical level are assumed to be more likely to make decisions that reflect value and respect for their patients. Educators in nursing curriculums are challenged to prepare students to practice in the complex health care environment and educational institutions are responsible to prepare students to meet these demands (Felton \& Parsons, 1987; Hsu \& Hsieh, 2009; Hunink, et al.; Mustapha \& Seybert, 1989; Scanlon, 1995). Since the work of nursing impacts lives, it is imperative that students are educated and socialized to make ethical decisions (Turner \& Bechtel, 1998). 


\section{Summary}

The intent of ethics education of nursing students is to develop skilled practitioners capable of detecting and responding to the ethical issues faced by nurses in practice (Comrie, 2012). Nursing curriculums vary in how the ethical reasoning ability of students is developed and the literature supports the inconsistency of how knowledge of ethics and ethical reasoning is taught throughout the various programs in the country (Comrie; Krawczyk, 1997; Nolan \& Markert, 2002). Debate continues regarding what is the best method of instruction of ethics in nursing students (Allmark, 1995; Dinç \& Görgülü, 2002; Kyle, 2008; Woods, 2005). Since nursing ethics is taught in many ways, from specialized classes to integration into the curriculum, it is difficult to know to what degree nursing students can reason ethically. Education in ethics and ethical theory provides the nurse with the tools necessary to reflect critically on the care they provide in their practice (Vanlaere \& Gastmans, 2007). It remains unclear how moral sensitivity can be developed in nursing students and there are few studies that attempt to identify the development process of moral sensitivity in nursing students (Comrie). Today's health care environment is challenging and complex. Learning environments need to be representative of the professional environment and the patient care situations encountered after graduation. 


\section{CHAPTER III METHODOLOGY}

Introduction

Nurses in practice face ethical challenges more and more frequently. To be able to practice as a professional nurse requires the ability to make ethical decisions. Progress in health care technology, global developments, and the graying of the population are factors influential to this trend. (Dinç \& Görgülü, 2002; Görgülü \& Dinç, 2007; Hsu, 2011). Nurses are expected to make autonomous decisions regarding the delivery of care to their patients within rigid time constraints when faced with complex care situations (Goethals, et al., 2010). Additionally, nurses have reported that when faced with ethical dilemmas, they experience a lack of confidence in the decision-making process when choosing a course of action (Ham, 2004). The complexity of health care and increased incidence of ethical challenges in nursing practice support the need for student nurses to develop ethical reasoning ability in order to be prepared to manage clinical situations with ethical considerations in their practice after graduation (Dinç \& Görgülü; Görgülü \& Dinç; Hsu).

The intent of nursing education is to develop skilled practitioners capable of detecting and responding to the complex issues faced by nurses in practice. Assisting the nursing student to develop ethical decision making abilities is crucial to this outcome. 
Active participation by the student facilitates this process (Görgülü \& Dinç, 2007). Nurses encounter difficult clinical situations daily; frequently assisting patients in making challenging decisions about their care or the care of a family member. The characteristics of nursing practice require that nursing students are capable of thinking ethically because they experience dilemmas in everyday situations (Hunink, van et al., 2009). Many clinical situations have ethical considerations that influence the choice of outcomes or solutions; often there is not a single solution appropriate for all clients (Lemonidou, et al., 2004).

Education in ethics and ethical theory provides the nurse with tools to reflect critically on the care they provide in their practice (Vanlaere \& Gastmans, 2007). Educators in nursing curriculums are responsible for and challenged to prepare students to practice in the complex health care environment. Adhering to an ethical practice is a required component of nursing education as described in the Essentials of Baccalaureate Education for Professional Nursing Practice (American Association of Colleges of Nursing, 2008) and specifically delineated in Essential VIII-Professionalism and Professional Values which states that baccalaureate graduates should be prepared to respond to numerous dilemmas and to make decisions within an ethical framework. Understanding the values that are brought to the relationship by each patient and anyone else involved in patient care is crucial to the quality of care. In addition to being an expectation of professional behavior, honesty and ethical practice impact patient safety (American Association of Colleges of Nursing, 2008). Candela and Bowles, (2008) explicitly indicated that there continues to be a dichotomy between practice and education. The complexity of health care and increased incidence of ethical challenges in 
nursing practice support the need for student nurses to develop ethical reasoning ability in order to be prepared to manage clinical situations with ethical considerations in their practice after graduation (Dinç \& Görgülü; Görgülü \& Dinç; Hsu). While ethics is not a science with verifiable answers, an understanding of ethical theory enables a nurse to practice in a comprehensive manner (Gibson, 1993).

Students need to be able to address and effectively manage ethical situations while they are students to ensure they can manage them as professionals. In order for nursing students to be prepared to practice effectively in clinical situations where ethical implications exist, the education process needs to be effective (Cameron, et al., 2001). Yet there is a scarcity of research addressing the issues that impact the ability of nursing education to develop ethical thinking ability in nursing students (Fowler \& Davis, 2013). Ulrich et al. (2010) concluded that nurses with less than five years of experience reported higher levels of stress associated with managing ethical issues encountered in their practice than nurses who had more than five years of experience. The documentation of high levels of stress in newer nurses combined with the scarcity of research on ethics education of nursing students provided the motivation to conduct this study.

This chapter contains a review of the research design and a description of the data collection process along with the statistical methods utilized in the data analysis. Additionally, a description of the participants' demographic characteristics and the limitations of the study are included. The purpose of this research was to examine the relationship between knowledge of the Code of Ethics for Nurses of graduating baccalaureate nursing students and choices of action and to explore individual characteristics that potentially contribute to this relationship in order to guide the 
educational process of nursing students. To accomplish this, the following research questions were addressed:

1. What is the relationship between knowledge of the Code of Ethics and choice of action in given scenarios by senior baccalaureate nursing students?

2. What impact does previous coursework on ethical content have on the relationship between knowledge of the Code of Ethics and choice of action in given scenarios?

3. What impact does previous clinical experience with ethical situations have on the relationship between knowledge of the Code of Ethics and choice of action in give scenarios?

\section{Research Design}

This was a quantitative, descriptive research study which utilized a survey. Surveys examine relationships between variables and can also assess attitudes, beliefs, preferences, and opinions (Leedy \& Ormrod, 2013; Salkind, 2012). Survey research is efficient since it is often completed in one contact with the sample population and is very accurate when conducted with minimal sampling error (Salkind). This research project included exploration of individual characteristics that potentially contributed to the relationship between the participants' knowledge and choice of action. The instrument used in this study is known as Ketefian's $J A N D$ and was originally developed over 40 years ago. The JAND consists of several stories about nursing practice that have ethical implications within them. The content of each story portrays some type of dilemma. Some examples of the types of dilemma include how to handle an unreported medication error, whether or not to report an impaired physician, what level of treatment to implement, and how to respond to unsafe staffing levels. Each story is followed by 
several questions. The participants responded twice to each question. Column A asked each participant to identify how appropriate a response was for the situation while column B asked each participant to identify how likely the action was to be implemented in their work setting.

At the time it was developed, the stories in the $J A N D$ were hypothetical but drawn from a pool of stories provided by practicing nurses. After the stories were constructed, additional practicing nurses discussed the dilemmas and generated the actions assigned as a response to each situation. Following this step, eight nationally recognized nurses rated each story on the degree the nursing action reflected ethical nursing behavior as defined by the Code of Ethics for Nurses providing content and face validity. At that time a pilot test of the tool conducted demonstrated an internal consistency test using coefficient alpha of 0.71 for column A and 0.78 for column B (Ketefian, 1982).

The instrument was revised in 2001 and 2007 to maintain continuity with the revisions of the Code of Ethics for Nurses and to increase clarity of the nursing actions included in each scenario. In 2001 this instrument was administered to 30 nurses from acute care settings to determine reliability. Coefficient alpha was used, yielding .71 for column A (26 usable cases) and .78 for column B (27 usable cases). In addition, the scores for the two columns were compared using a $t$-test for non-independent samples, resulting in a $t$ value of $4.403, d f=29, p=.000$. Following the administration of the test to the above sample, revisions were made in the instrument to achieve greater clarity among the nursing actions and the October 2007 version of the JAND was developed at that time. This version is similar but not exactly the same as the version on which the above 
results were obtained (S. Ketefian, personal communication, December 2, 2012). The October 2007 version was used in this study.

On a copy of the $J A N D$ available to the investigator only, the responses are identified as whether a given nursing action is recommended, not recommended, or ambiguous. If a response is ambiguous it does not fit clearly in recommended or not recommended category. An example of ambiguous activity is where a nurse would report a medication error by calling a relevant party to report the error without identifying herself or himself. Reporting the errors is appropriate, but not identifying oneself and providing more relevant information shows a lack of accountability and follow-through. The JAND included a number of items that were characterized as ambiguous, meaning that it is hard to find clear evidence in the Code of Ethics whether such action is a good or poor choice. (S. Ketefian, personal communication, December 2, 2012). The ambiguous items were not included in any of the calculations because of the difficulty in interpreting the responses.

In column A, the participant answered regarding what action the nurse should take and in column B, the participant answered regarding how likely the nurse was to follow through with the action identified. Participants responded separately for column A and for Column B using a Likert type scale of strongly agree=5; agree=4; neutral=3; disagree $=2 ;$ strongly disagree $=1$. Thus, there will be separate scores for each item from the entire sample used to calculate the sample means for column A and for column B. The numerical average of all responses for each of the columns became the score (Ketefian, 1981; Ketefian, 1982). Overall, the participants responded to 148 items. Since the desired response for the items identified as recommended was strongly agree $=5$, and 
the response for the items identified as not recommended was strongly disagree $=1$; the items that were identified as not recommended were reverse scored for both columns A and $\mathrm{B}$. This allowed all of the scores to be added together when calculating the mean score for both knowledge and action.

Research Question 1

What is the relationship between knowledge of the Code of Ethics and choice of action in given scenarios by senior baccalaureate nursing students?

The relationship between the action and the likelihood that the action would be implemented appropriately was determined through the use of correlational statistics. Using descriptive statistics, the researcher determined the mean for each response for each action in column A and Column B. Comparison of the mean for each action to the likelihood of implementation of that action illustrated the strength of the relationship between the action and implementation of the action. For example, did the subject recognize whether or not the action was recommended/not recommended and indicate that the likelihood of taking the action was consistent with what they knew to be correct and appropriate, specifically Pearson's $r$. In order to answer this question, the variables were the knowledge of a desired response and the action chosen to respond to the situation.

Research Question 2

What impact does previous coursework on ethical content have on the relationship between knowledge of the Code of Ethics and choice of action in given scenarios? 
In addition to administering the $J A N D$, this researcher used a separate information sheet to collect details that identified demographic information and additional characteristics which potentially contributed to the ability of the nursing students to reason ethically. One question on the demographic survey asked each participant to rank how much college credit he or she had earned in courses where the content was ethics. The participants were then divided into two groups; Group 1 participants had earned six or less hours of college credit; Group 2 had earned seven hours or more of college credit. The structure of the questionnaire made the division very clear.

The relationship between the action and the likelihood that the action would be implemented appropriately was determined through the use of correlational statistics. Specifically Pearson's $r$ was determined for each subgroup; those who had earned six hours or less of credit in ethics coursework and those who had earned seven or more. In other words, did an increase in college coursework in ethical content result in a stronger correlation between knowledge and action. To determine this, the correlation coefficient of each subgroup was converted into a $z$ score and then compared to determine if the difference between the correlation coefficients were significant Fisher (1921). A $z$ score of 1.96 was needed to be significant. Research Question 3

What impact does previous clinical experience with ethical situations have on the relationship between knowledge of the Code of Ethics and choice of action in given scenarios?

Since this question is similar in structure to Research Question 2 the same procedure was followed. One question on the separate information sheet to collect that 
demographic information and additional characteristics asked each participant to indicate if he or she had ever had to make important or critical decisions about the health care of another individual. Using the categories of yes or no, the participants were divided into two groups. Group 1 had been involved in making decisions about the health care of another individual; Group 2 had not been involved in making decisions about the health care of another individual. The relationship between the action and the likelihood that the action would be implemented appropriately was determined through the use of correlational statistics. Specifically Pearson's $r$ was determined for each subgroup; those who had experience making decisions about the health care of others and those did have experience making decisions about the health care of others. In other words, did an involvement in making ethical decisions about the health care of another individual result in a stronger correlation between knowledge and action. To determine this, the correlation coefficient of each subgroup was converted into a $z$ score and then compared to determine if the difference between the correlation coefficients were significant Fisher (1921). A $z$ score of 1.96 was needed to be significant.

\section{Population}

The population studied was senior nursing students in baccalaureate nursing programs enrolled in the last semester of classes before graduating. The sample was obtained from several colleges of nursing throughout a state located in the Midwest. These students varied in gender, age, previous life experiences, and coursework not related to their nursing curriculum. Participants were recruited from a class that is required of all graduating seniors at each of the colleges. The participants were a convenience sample of senior nursing students, specifically nursing students who were in 
their last semester and planning to graduate at the end of that semester. Each of the colleges graduates students both in the fall and the spring. One of the colleges consists of two campuses with approximately 30 students graduating per campus each semester. A goal of 200 participants was established but only 183 participants completed the surveys. All of the data were collected from the graduates in the fall semester. Of the 183 surveys returned only 174 were used in data analysis; nine were omitted because they were incomplete.

\section{Analytical Methods}

Using data from the separate information sheet that accompanied the JAND the researcher identified demographic information and additional characteristics which potentially contributed to the ability of the nursing students to reason ethically. Regarding ethnicity, $84.5 \%$ of the sample were Caucasian $(n=147), 4.6 \%$ were African American $(n=8), 7 \%$ were Asian $(n=4), 4.6 \%$ identified as of mixed ethnicity $(n=8)$, and $2.3 \%(n=4)$ preferred not to answer. Table 1 and Figure 1 illustrate the ethnicity of the sample population. The representation of gender in the sample was $87.4 \%$ were female $(n=153)$ and $12.1 \%$ were male $(n=21)$. Table 2 and Figure 2 illustrate the distribution of gender in the sample population. Regarding age, the majority of the students were young, between the ages of $20-24$ at $52.3 \%(n=91), 27.6 \%$ of the population were $25-29(n=48), 9.2 \%$ were between the ages of 30-34 $(n=16), 5.7 \%$ ranged from $35-39(n=10), 3.4 \%$ were in the 40-45 age range $(n=6)$, and $1.7 \%(n=3)$ were between the ages of $46-50$. Table 3 and Figure 3 illustrate the differences in the sample population with regard to age. 
Table 1

Ethnicity of the Sample Population

\begin{tabular}{lcc}
\hline Ethnicity & Frequency & Percent \\
\hline Not Indicated & 4 & 2.3 \\
Black/African American & 8 & 4.6 \\
White/ Caucasian & 147 & 84.5 \\
Asian & 7 & 4.0 \\
Mixed & 8 & 4.6 \\
\hline Total & 174 & 100.0 \\
\hline
\end{tabular}

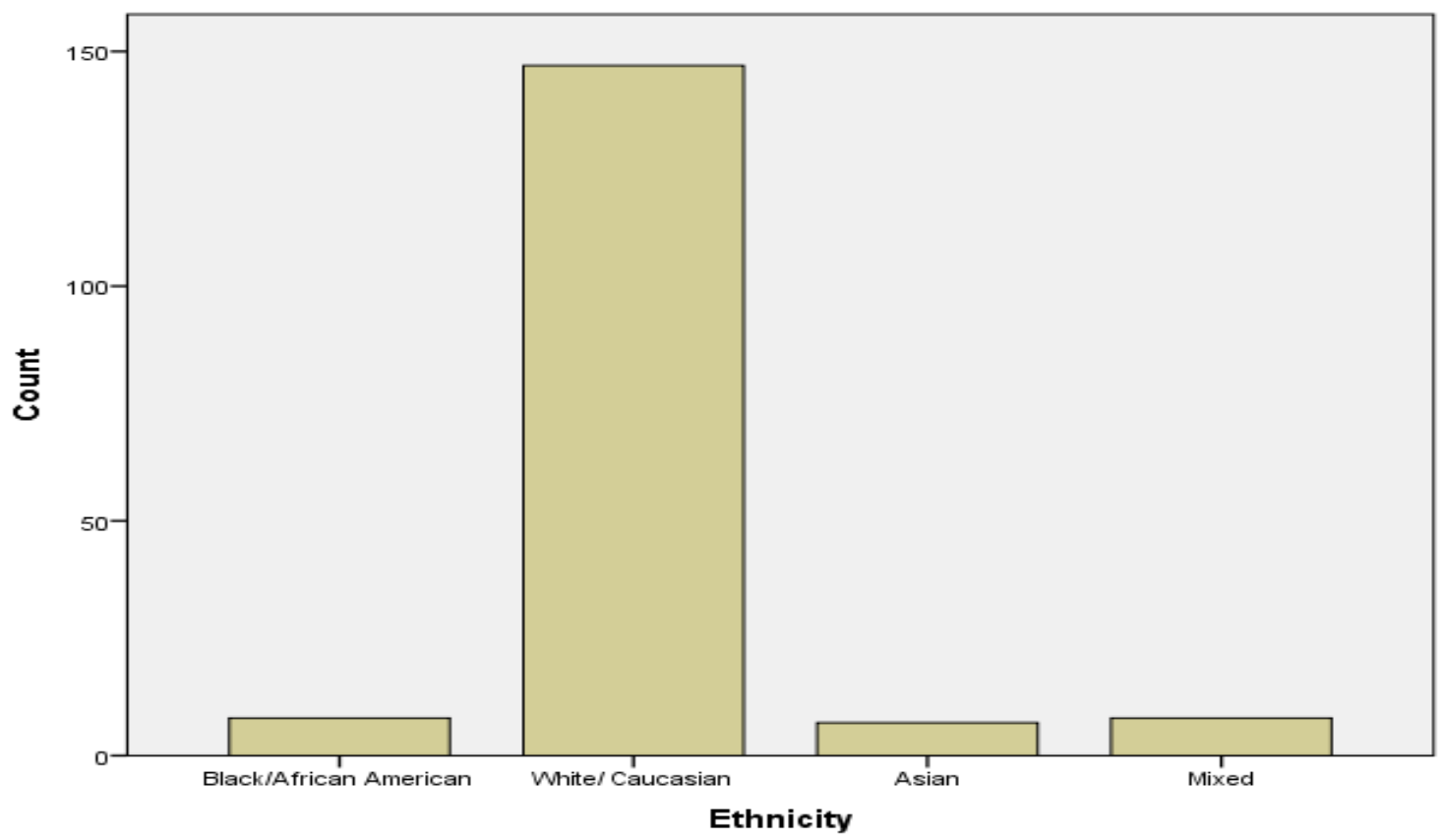

Figure 1. Ethnicity of the Sample Population 
Table 2

Gender of Participants

\begin{tabular}{ccc}
\hline Gender & Frequency & Percent \\
\hline Male & 21 & 12.1 \\
Female & 153 & 87.9 \\
\hline Total & 174 & 100.0 \\
\hline
\end{tabular}

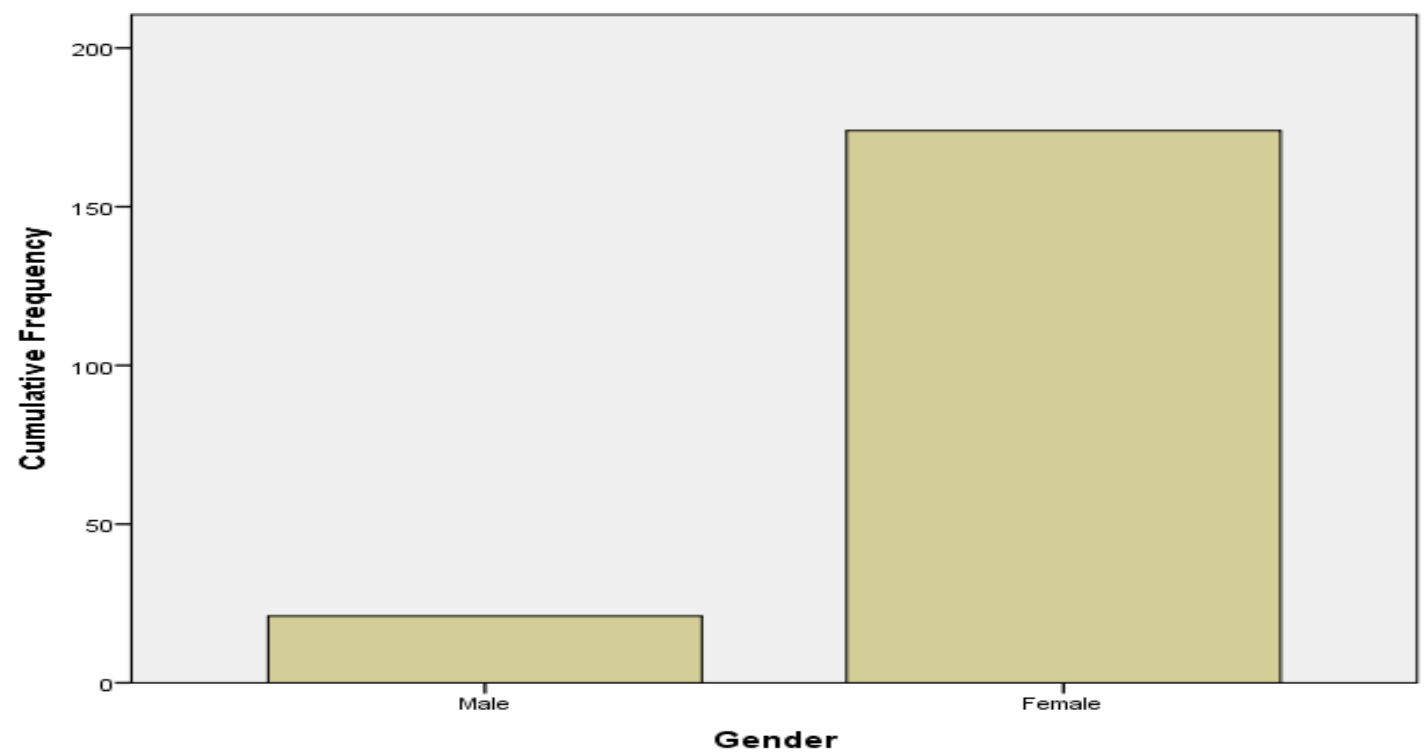

Figure 2. Gender of Participants 
Table 3

Age of Participants

\begin{tabular}{ccc} 
Age & Frequency & Percent \\
\hline $20-24$ & 91 & 52.3 \\
$25-29$ & 48 & 27.6 \\
$30-34$ & 16 & 9.2 \\
$35-39$ & 10 & 5.7 \\
$40-45$ & 6 & 3.4 \\
$46-50$ & 3 & 1.7 \\
\hline Total & 174 & 100.0 \\
\hline
\end{tabular}

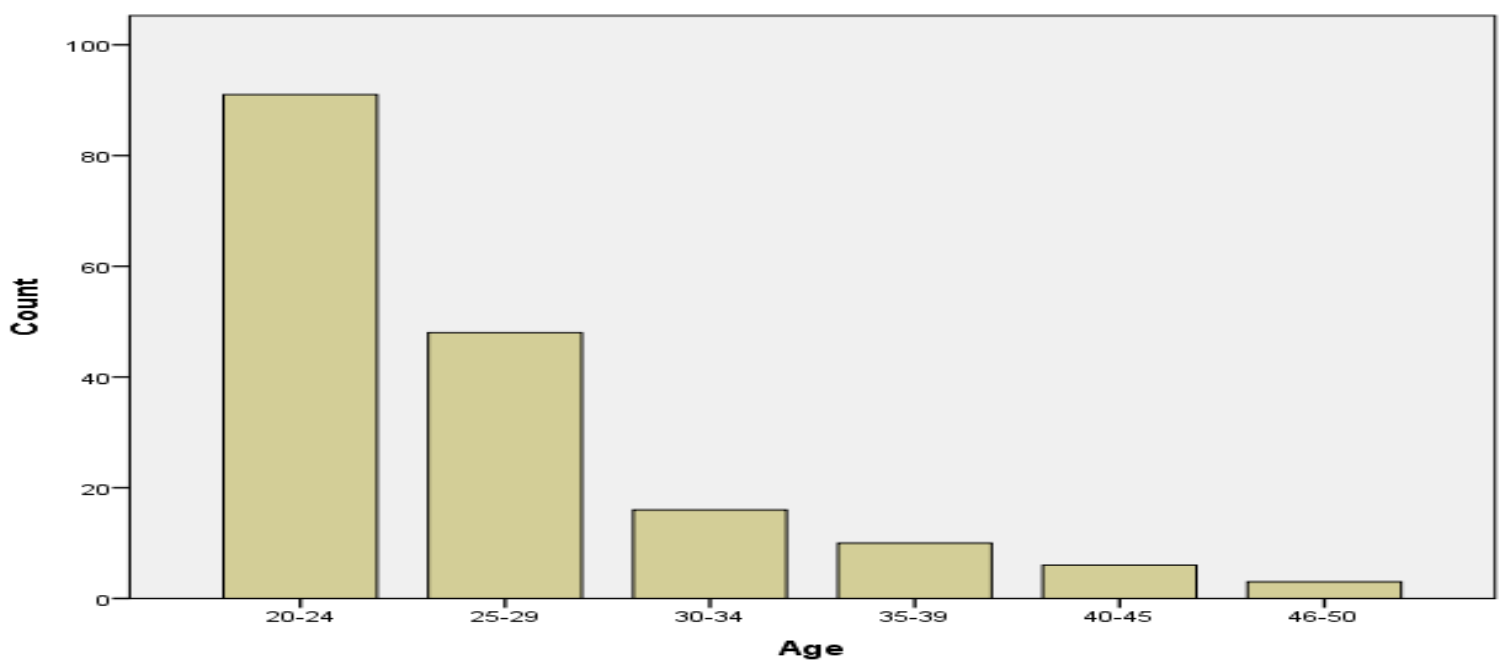

Figure 3. Age of Participants

\section{Data Collection}

Data collection was done by the researcher with the cooperation of the colleges and their faculty members. The colleges participating in the study are located in the central and western part of a state in the Midwest. The researcher sought and received Institutional Review Board (IRB) approval from the educational organization overseeing 
the research process and then approached the administration of each participating college. Compliance with the policies and procedures that directed the process of working with human subjects was met at each of these colleges and permission received to approach the faculty at the school. At that time the researcher was given a day and time when a meeting with the students during class time could occur. With the exception of one school, the researcher traveled to the separate campuses to attend the class and administered the instruments used to collect the data. Scheduling conflicts prevented the researcher from attending the class at one school. In this situation a video made of the researcher explaining the project and asking for consent along with a written script was sent to the lead faculty of the course. This faculty member then collected the surveys and returned them to the researcher.

All participants provided voluntary and informed consent. The participants were asked to provide some personal information and to complete the questionnaire consisting of patient care vignettes with moral or ethical implications present in each scenario, consequently; the risk to the participants was minimal. When the administering the questionnaire, the demographic information about the participants was collected using a separate information sheet coded to align with the completed questionnaire. The participants did not need to identify themselves on the survey form or the demographic information sheet, so anonymity was preserved. The diversity of the students who comprised the sample prevented identification by any of the variables. The demographic variables identified were age, gender, religion, other academic degrees held, previous experience with ethical situations and additional college credit earned in ethics courses. 


\section{Limitations}

The sample used in this study was one of convenience consisting of senior nursing students at five colleges within a central geographic region of one state in the Midwest. The possibility of limited representation is a risk for this study since the sample was one of convenience. Although there are several hundred miles between these colleges, this is a small area when considering the population of senior nursing students in the United States.

While diversity was present in the sample population it was not as broad as preferred. The majority of the students were Caucasian ( $n=147$ or $84 \%$ ), between the ages of $20-24(n=91$ or $52 \%)$, and female ( $n=153$ or $87.4 \%)$. If the range of the student age was extended, 139 students or $79.9 \%$ of the population was in the age range of 20-29. It is difficult to know if this is an accurate representation of the senior nursing student population or if the research sample was overrepresented by young Caucasian females.

Participation was voluntary, but since data collection occurred as part of class time it is possible that any student who did not want to participate felt pressure to complete the survey anyway. Examples illustrating this include a student who marked the tool with the same value throughout the survey and then used comments to apologize for messing with the research, and another student who signed the consent, sat through the class time allowed to complete the survey, and then submitted a blank form.

Another limitation was the length of the tool. Each student responded to 148 items plus the questions on the demographic tool. Although it only took an average of 30 minutes to complete and the time was scheduled during class, this could be perceived as a long time in a population that is used to multiple stimuli and instant responses. At least 
two students commented on the length of the survey, the time it took to complete, and indicated the stories were repetitive.

Leedy and Ormrod (2013) noted that survey research is dependent on selfreported information. Respondents may answer according to what they think the researcher may want to hear or in a way that portrays them in a favorable perspective. Survey research generally requires participants to respond at that point in time making it is also possible that the participants may not have previously thought about a situation and answer spontaneously without the benefit of insight into the circumstances. When this occurs the answers may lack context and only represent recent events (Leedy \& Ormrod).

\section{Summary}

The purpose of this research was to correlate the knowledge of the Code of Ethics for Nurses of graduating nursing students to choices of action in a clinical situation and included exploration of individual characteristics that could potentially contribute to the students' knowledge and choice of action. Whether or not nursing students are adequately prepared to make ethical decisions at the time of graduation is not clear (Dierckx de Casterlé, et. al., 1997; Krawczyk, 1997; Nolan \& Markert, 2002). This study explored how knowing related to action. Specifically, what knowledge did senior baccalaureate students possess on the Code of Ethics for Nurses and how did that knowledge correlate to action in specific scenarios.

The instrument used was the Judgment About Nursing Decisions (JAND). This instrument was a questionnaire which consisted of eight patient care vignettes with moral or ethical implications present in each story. Each vignette was followed by a series of 
nursing actions. Aligned with each nursing action were two columns: in Column A, using a Likert type scale, the participant answered regarding what the nurse should do, and in Column B, again using a Likert type scale, the participant decided how likely the nurse was to follow through with the action identified. An information sheet collecting additional demographic data about the participants was used to determine if individual characteristics influenced the knowledge and understanding of the student. 


\section{CHAPTER IV}

\section{FINDINGS AND CONCLUSIONS}

\section{Introduction}

The intent of nursing education is to develop skilled practitioners capable of detecting and responding to the complex issues faced by nurses in practice. In order to accomplish this, development of the ethical decision making abilities of the nursing student is necessary. Active participation by the student facilitates this process (Görgülü \& Dinç, 2007). In order to guide the educational process of nursing students, the purpose of this research was to examine the graduating nursing students' knowledge of the Code of Ethics for Nurses and choices of action. The study also examined individual characteristics of the student to determine their impact on the students' ethical knowledge and choice of action. To accomplish this, the following research questions were addressed:

Research Question 1. What is the relationship between knowledge of the Code of Ethics and choice of action in given scenarios by senior baccalaureate nursing students?

Research Question 2. What impact does previous coursework on ethical content have on the relationship between knowledge of the Code of Ethics and choice of action in given scenarios?

Research Question 3. What impact does previous clinical experience with ethical situations have on the relationship between knowledge of the Code of Ethics and choice of action in given scenarios? 
In order to answer these questions the instrument Ketefian's (JAND) was utilized to determine nursing students' knowledge and choice of action regarding ethical dilemmas in given scenarios. In addition to the JAND, an additional assessment tool identified demographic data that allowed the researcher to explore individual characteristics that potentially contributed to the relationship between the participants' knowledge and choice of action. This chapter contains an overview of the results obtained through this research project along with a discussion of the implications of the results and recommendations for future actions.

\section{Findings}

\section{Research Question 1}

What is the relationship between knowledge of the Code of Ethics and choice of action in given scenarios by senior baccalaureate nursing students?

In order to answer the first research question the researcher administered a survey known as Ketefian's (JAND). The JAND consists of several stories about nursing practice that have ethical implications within them. The content of each story portrays some type of dilemma. Some examples of the types of dilemma include how to handle an unreported medication error, whether or not to report an impaired physician, what level of treatment to implement, and responding to unsafe staffing levels. Each story is followed by several questions. Each participant responded twice to every question. Column A asked the participant to identify how appropriate a response was for the situation while column B asked the participant to identify how likely the action was to be implemented in their work setting. 
Participants responded separately for column A and for Column B using a Likert type scale of strongly agree $=5$; agree $=4$; neutral $=3$; disagree $=2 ;$ strongly disagree $=1$. Thus, a separate score exists for each item from the entire sample used to calculate the sample means for column A and for column B. The numerical average of all responses for each of the columns became the score (Ketefian, 1981; Ketefian, 1982). Overall, the participants responded to 148 items. Since the desired response for the items identified as recommended was strongly agree $=5$, and the response for the items identified as not recommended was strongly disagree $=1$; the items that were identified as not recommended were reverse scored for both columns A and B. This allowed all of the scores to be added together when calculating the mean score for both knowledge and action.

The relationship between knowledge and the likelihood that the action would be implemented appropriately was determined through the use of correlational statistics, specifically Pearson's $r$. In this situation the variables are the knowledge of a desired response and the action chosen to respond to the situation. Using descriptive statistics, the researcher determined the mean for each response for each action in column A and Column B. Comparison of the mean for each action to the likelihood of implementation of that action illustrated the strength of the relationship between the action and implementation of the action. For example, did the subject recognize whether or not the action was recommended/not recommended and indicate that the likelihood of taking the action was consistent with what they knew to be correct and appropriate. The mean values for knowledge and action are provided in Table 4. The relationship between knowledge and action in senior baccalaureate nursing students was positive and 
significant $r(172)=.45, p<.01$; yet moderate in nature. Although a moderate relationship is not an association beyond dispute, it demonstrates that the relationship is adequate and strong enough to indicate a connection between the variables (Salkind, 2011). The relationship of knowledge to action is illustrated in Figure 4.

Table 4

Mean Value of Responses for Knowledge and Action

\begin{tabular}{lcc}
\hline & Knowledge & Action \\
\hline$n$ & 174 & 174 \\
Mean & 153.477 & 137.149
\end{tabular}

Std. Deviation $\quad 10.5654 \quad 15.3777$

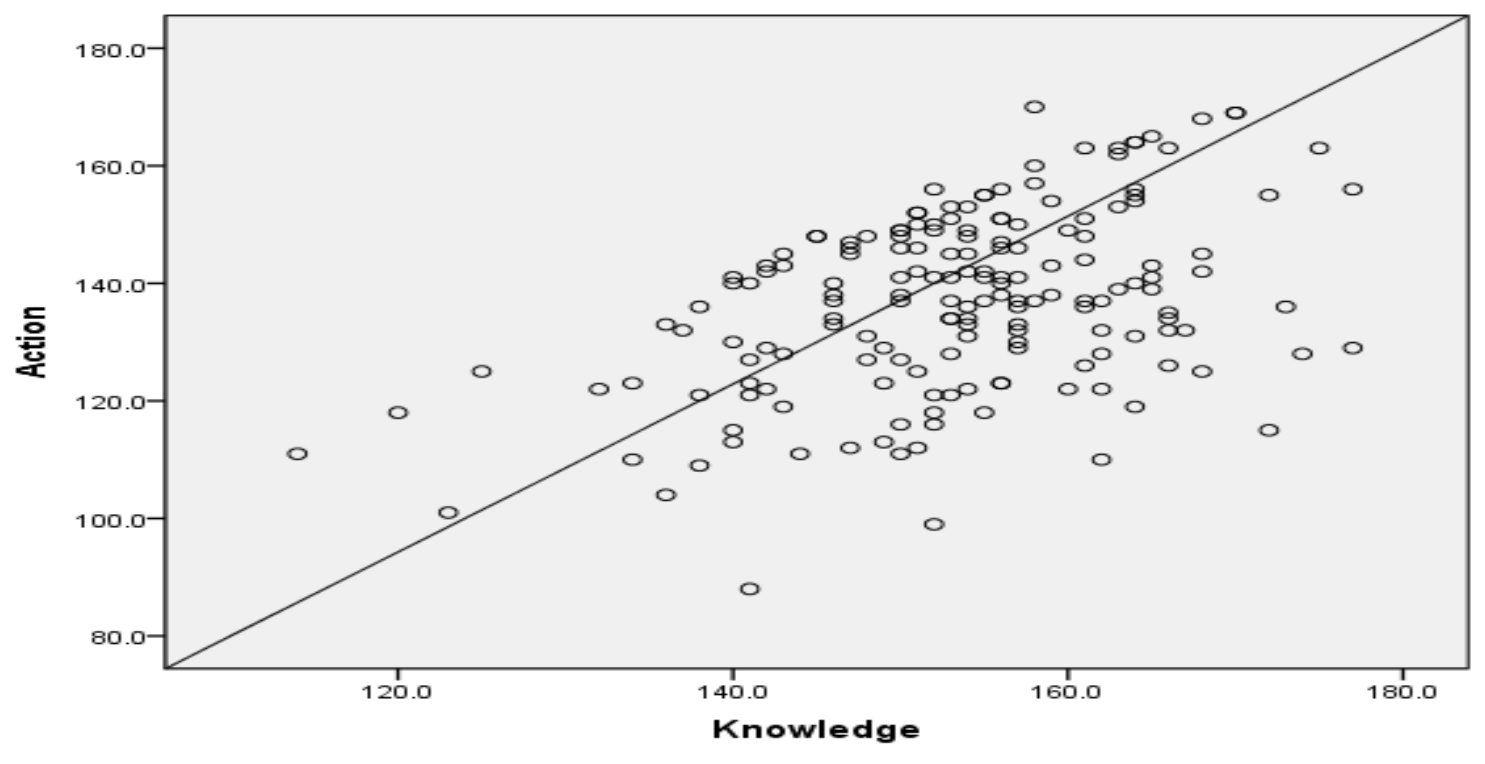

Figure 4 Correlation of Knowledge to Action 


\section{Research Question 2}

What impact does previous coursework on ethical content have on the relationship between knowledge of the Code of Ethics and choice of action in given scenarios?

In addition to administering the JAND, this researcher used a separate information sheet to collect details that identified information about characteristics which potentially contributed to the ability of the nursing students to reason ethically. One question on this survey asked each participant to rank how much college credit he or she had earned in courses where the content was ethics. The participants were then divided into two subgroups based on the amount of college coursework in ethical content completed. Group 1 participants had earned six or less hours of college credit; Group 2 had earned seven hours or more of college credit. The structure of the questionnaire made the division very clear.

The relationship between the action and the likelihood that the action would be implemented appropriately was determined separately for each subgroup through the use of correlational statistics; specifically Pearson's $r$. In other words, did an increase in college coursework in ethical content result in a stronger correlation between knowledge and action. For the participants in group 1: $r(155)=.449, p<.01$; while the participants in group 2: $r$ $(19)=.458, p<.05$.

The difference in the correlation coefficients is small; but the correlation coefficient for each group indicated a positive, significant, and moderate correlation between knowledge and action that was dependent on previous coursework on ethical content. Therefore, in order to determine if it was significant, a standard $z$ score was obtained using a series of calculations developed by Fisher (1921). The correlation coefficient of each subgroup was 
converted into a $z$ score and then compared to determine if the differences in the degree of correlation were significant. A z score for a $95 \%$ confidence interval is 1.96 so this was the minimum value needed to be significant. The $z$ score comparing the correlation coefficients for the two subgroups involving college coursework on ethics was 0.04. Since the $z$ score was not significant, the conclusion drawn was that the strength of the correlation did not change with increased coursework.

\section{Research Question 3}

What impact does previous clinical experience with ethical situations have on the relationship between knowledge of the Code of Ethics and choice of action in give scenarios?

Since this question is similar in structure to the previous question, the same procedure was followed. One question on the separate information sheet used to collect additional information asked each participant to indicate if he or she had ever made or shared the responsibility for making important or ethical decisions about the health care of another individual. Using the categories of yes or no, the participants were divided into two groups. Group 1 participants had been involved in making ethical decisions about the health care of another individual; Group 2 participants had not been involved in making ethical decisions about the health care of another individual.

The relationship between the action and the likelihood that the action would be implemented appropriately was determined separately for each subgroup through the use of correlational statistics; specifically Pearson's $r$. In other words, did an involvement in making ethical decisions about the health care of another individual result in a stronger correlation between knowledge and action. For the participants in group 1: $r(24)=.575, p<.01$; for the participants in group 2: $r(150)=.431, p<.01$. 
The difference in these correlation coefficients is larger than the difference seen with the previous variable of previous coursework on ethical content. The correlation coefficient for each group indicated a positive, significant, and moderate correlation between knowledge and action that was dependent on previous experience with making ethical decisions about the health care of another individual. Although the correlation coefficient for both groups was positive and moderate, the correlation coefficient in the group who had previous experience making decisions was larger indicating a stronger relationship. In order to determine if the difference between the correlation coefficient of the two subgroups was significant, the correlation coefficient of each subgroup was converted into a $z$ score and then compared. A $z$ score for a $95 \%$ confidence interval is 1.96 so this was the minimum value needed to be significant. The $z$ score comparing the correlation coefficients for those with previous experience with making ethical decisions about the health care of another individual was 0.83 and was not significant.

This question was then expanded to include any type of experience in health care. Again the participants were divided into two groups; Group 1 had experience in health care prior to starting in nursing school; this experience was general and included work such as nursing assistants and pharmacy technicians. Group 2 did not have any experience in health care prior to starting in nursing school. For the participants in group $1, r(80)=.463, p<.01$; the participants in group $2, r(92)=.421, p<.01$. Both indicate a significant, positive, and moderate correlation between knowledge and action that is dependent on previous experience in health care.

In order to determine if the difference between the two subgroups was significant, the correlation coefficient of each subgroup involving previous health care experience was 
converted into a $z$ score and then compared to determine if the differences in the degree of correlation were significant. A z score for a $95 \%$ confidence interval is 1.96 so this was the minimum value needed to be significant. The $z$ score comparing the correlation coefficients for experience in health care was 0.34 . This value was also not significant indicating that the strength of the correlation did not change with experience.

See Table 5 for a comparison of the correlation coefficients $(r)$ and $z$ values for each variable.

\section{Table 5}

Comparison of Variables

\begin{tabular}{|c|c|c|c|c|c|c|}
\hline Variable & \multicolumn{2}{|c|}{ Education } & \multicolumn{2}{|c|}{ Previous Decision } & \multicolumn{2}{|c|}{ Previous Experience } \\
\hline Category & $\leq 6 \mathrm{hrs}$ & $\geq 7 \mathrm{hrs}$ & No & Yes & Yes & No \\
\hline$n$ & 155 & 19 & 150 & 24 & 80 & 92 \\
\hline$r$ & .449 & .458 & .431 & .575 & .463 & .421 \\
\hline$z$ & \multicolumn{2}{|c|}{0.04} & \multicolumn{2}{|c|}{0.83} & \multicolumn{2}{|c|}{0.34} \\
\hline
\end{tabular}

Conclusions

This study explored how ethical knowledge related to action in senior baccalaureate nursing students with regard to ethical situations. Specifically, what knowledge did senior baccalaureate students possess on the Code of Ethics for Nurses and how did that knowledge correlate to action in specific scenarios. Nursing curriculums vary in how the ethical reasoning ability of students is developed; making it difficult to know to what degree that students can reason ethically. The substance of this study supports the premise that there is a relationship between ethical knowledge and action in senior nursing students. In this study there was a positive correlation of moderate 
strength between ethical knowledge and action in senior baccalaureate nursing students that was maintained even with additional coursework and experience with ethical situations increased. The correlation between knowledge and action was strongest in the group of participants who had previous experience with making ethical decisions about the health care of another individual. Görgülü \& Dinç (2007) described how active participation by the student nurse facilitated progress of the ethical decision making process. Thus, it would seem logical that increased instruction and experience with ethical content would increase the abilities of the student, yet the data did not support that.

Although the data supported that a positive relationship existed between ethical knowledge and action, there was not a significant difference between the correlation coefficient of the sub groups to indicate that more experience or education was significant. While the correlation coefficient increased and was stronger in the groups with education and experience, the difference was not significant. This could possibly be due to a considerable size difference in the number of participants between the groups. The subgroup with more education and the subgroup with previous experience making decisions of an ethical nature were substantially smaller than the groups who had less education and no previous experience making a decision about care. Because of the difference in size, there may not have been enough participants in these groups to accurately reflect a difference. See Table 2 for a comparison of the number of participants in each group. 
Implications and Recommendations

It is important to note the while many nursing programs require a course in the ethics of health care; others only require a generic course on ethics that is not specific to nursing or even health care. Additional options include embedding the content throughout all courses in the curriculum or including instruction on ethical principles only if situations are encountered during a clinical practicum (Aroskar, 1977; Comrie, 2012; Dierckx de Casterlé, et al., 1997; Krawczyk, 1997; Nolan \& Markert, 2002). People, when they are patients, trust their lives and general health to the nurses who are responsible for their care. An ethical dimension of care is essential and encompasses all aspects of nursing care, not just the beginning and end of life (Bishop \& Scudder, 1990, Vanlaere \& Gastmans, 2011).

Since a variety of methods can result in inconsistency between programs, the most obvious implication of this research is that more research is needed to determine which characteristics, if any, of nursing students will strengthen the relationship between ethical knowledge and action. Larger and more diverse samples may produce significant results to determine which characteristics influence the relationship between knowledge and action. The lack of significance in this study could be explained by the large difference in the number of participants within each subgroup.

Because of an increased awareness of the students' ability to evaluate and respond to ethical situations in the clinical setting nurse educators in colleges of nursing need to assess their curriculum to determine how ethical content is addressed and whether not students are being prepared to manage ethical situations in the clinical setting; not just 
recognize them. Education in ethics and ethical theory provide the nurse with tools to reflect critically on the care they provide in their practice (Vanlaere \& Gastmans, 2007).

An ethical dilemma is a situation where conflict exists between the values of an individual or his or her choices of action with arguments possible for either position (Cooper, 2004; Gibson, 1993). The ability to make decisions that are ethically based is often learned through practice; consequently, students who were fortunate to encounter ethical situations through their clinical practicum would have an advantage over students who did not. As educators, it is important to assist graduating nurses to develop their ability to reason in an ethical manner (Park, et al., 2012). However, students cannot depend on chance exposure to a clinical situation in order to develop ethical reasoning abilities, they need opportunities to address and effectively manage ethical situations while they are students to ensure they can manage them as professionals. Nursing educators needs to ensure exposure to appropriate learning opportunities in order to assist the student to make the transition from student to practicing nurse.

In order for nursing students to be prepared to practice effectively in clinical situations where ethical implications exist, the education process needs to be effective (Cameron, et al., 2001). Instruction in the theory of ethics to nursing students, along with exposure to ethical dilemmas in a clinical environment, is necessary to prepare safe and competent practitioners who are able to manage clinical situations with ethical considerations (Turner \& Bechtel, 1998). This could be managed through use of simulation scenarios. Scenarios can be case studies that are discussed in a classroom setting or high-fidelity simulation designed to mimic the clinical situation in a laboratory setting. The use of simulation where students can work through the process of making 
ethical decisions in a controlled environment may be especially beneficial since the strongest relationship between knowledge and action was identified in the group of participants who had participated in making ethical clinical decisions. Analyzing case studies and utilizing simulation scenarios with ethical dilemmas included are recommended teaching methodologies supported by the results of this study and others (Comrie, 2012).

Dierckx de Casterlé, et al. (1996) described ethical nursing practice as a link to action, stating that reasoning and implementation of action both need to be present and ethical. Ethical practice in nursing is more than knowing and understanding the events of a clinical situation; the nurse needs to be able to implement appropriate actions to meet the needs of the patient. While college credit in courses on ethics, previous experience with making health care decisions of an ethical nature, and even general experience in health care influenced the results, they did not significantly impact the relationship between knowledge and action in this study. However, even though it was not significant, the data demonstrated a trend that indicated a difference was present. The lack of significance could be explained by the large difference in the number of participants within each subgroup. Additional research with larger and more diverse samples may produce different results and is the primary recommendation drawn from these results.

In the today's complex health care environment, nurses must to be able to provide ethical care to patients with complex needs. Providing this level of care is timeconsuming and can be challenging. Often the healthcare needs of the patients require that nurses assist the patient in making choices between treatments that influence outcomes; many times these choices require reflection on the ethical implications of each option. 
Ethical knowledge or even the ability to reason in an ethical manner would not be necessary if only one right solution existed for every dilemma and that solution was easy to implement (Ulrich, 2012).

Ethics is a deeply personal process embedded in the work of nursing, making the development of pedagogy for student instruction challenging (Doane 2002; Doane, et al., 2004). Ethical competence is the ability to recognize when situations are ethical in nature, identify different potential solutions, and then take action. Nurses build therapeutic, interpersonal relationships that are caring in order to support and empower their patients and their patient's families (Lemonidou, et al., 2004). As a therapeutic discipline that accepts that the attributes of caring and nurturing are integral to practice, ethics is a natural component of the nursing profession supporting the necessity of including the concepts in the educational process. 


\section{REFERENCES}

American Association of Colleges of Nursing. (2008). The essentials of baccalaureate education for professional nursing education. Retrieved from http://www.aacn.nche.edu/education-resources/baccessentials08.pdf

Allmark, P. (2005). Can the study of ethics enhance nursing practice? Journal of Advanced Nursing 51(6), 618-624.

Arman, M., \& Rehnsfeldt, A. (2007). The "little extra" that alleviates suffering. Nursing Ethics, 14(3), 372-386.

Aroskar, M. A. (1977). Ethics in the nursing curriculum. Nursing Outlook, 25(4), 260264.

Baxter, P. E., \& Boblin, S. L. (2007). The moral development of baccalaureate nursing students: Understanding unethical behavior in classroom and clinical settings. Journal of Nursing Education. 46(1), 20-27.

Beckett, A., Gilbertson, S., \& Greenwood, S. (2007). Doing the right thing: Nursing students, relational practice, and moral agency. Journal of Nursing Education, 46(1), 28-32.

Benner, P. (1982). From novice to expert: The Dreyfuss model of skill acquisition. American Journal of Nursing, 82(3), 402-407.

Benner, P. (1991). The role of experience, narrative, and community in skilled ethical comportment. Advances in Nursing Science, 14(2), 1-21. 
Benner, P., Sutphen, M., \& Leonard-Khan, V. (2008). Formation and everyday ethical comportment. American Journal of Critical Care, 17(5), 473-476.

Bishop, A. H. \& Scudder, J. R., (1990). The Practical, Moral, and Personal Space of Nursing. Albany, NY: State University of New York Press.

Bishop, A. H. \& Scudder, J. R., (1996). Nursing Ethics: Therapeutic Caring Presence. Boston, MA: Jones and Bartlett.

Bosek, M. C. D., \& Savage, T. (2007). The Ethical Component of Nursing Education, Philadelphia, PA: Lippincott, Williams, and Wilkins.

Callister, L. C., Luthy, K., Thompson, P., \& Memmott, R. J. (2009). Ethical reasoning in baccalaureate nursing students. Nursing Ethics, 16(4), 499-510.

Callister, L. C., Ravert, P., Stoneman, E., \& Matsuma, G. (2004). Ethical reasoning in capstone students. International Journal for Human Caring, 8(2), 54-60.

Cameron, M. E., Schaffer, M., \& Park, H. (2001). Nursing students' experience of ethical problems and use of ethical decision-making models. Nursing Ethics, 8(5), 432447.

Candela, L., \& Bowles, C. (2008). Recent RN graduate perceptions of educational preparation. Nursing Education Perspectives, 29(5), 266-271.

Comrie, R. W. (2012). An analysis of undergraduate and graduate student nurses' moral sensitivity. Nursing Ethics 19(1), 116-127. doi:10.1177/0969733011411399

Cooper, D. E. (2004). Ethics for Professionals in a Multicultural World, (4 ${ }^{\text {th }}$ ed.). Upper Saddle River, NJ: Prentice Hall. 
Dierckx de Casterlé, B., Grypodonck, M., Vuylsteke-Wauters, M., \& Janssen, P. (1997). Nursing students' responses to ethical dilemmas in nursing practice. Nursing Ethics 4(1), 12-28.

Dierckx de Casterlé, B., Janssen, P., \& Grypodonck, M. (1996).The relationship between education and ethical behavior of nursing students. Western Journal of Nursing Research, 18(3), 330-350.

Dierckx de Casterlé, B. D., Izumi, S., Godfrey, N., \& Denhaerynck, K. (2008). Nurses’ responses to ethical dilemmas in nursing practice: Meta-analysis. Journal of Advanced Nursing, 63(6), 540-549. doi:10.1111/j.1365-2648.2008.04702.x

Dinç, L., \& Görgülü, R. S. (2002). Teaching ethics in nursing. Nursing Ethics, 9(3), 259268.

Doane, G. H. (2002). In the spirit of creativity: The learning and teaching of ethics of ethics in nursing. Journal of Advanced Nursing, 39(6), 521-528.

Doane, G., Pauly, B., Brown, B., \& McPherson, G. (2004). Exploring the heart of ethical nursing practice: Implications for ethics education. Nursing Ethics, 11(3), 240253.

Durgahee, T. (1997). Reflective practice: Nursing ethics through story telling. Nursing Ethics, 4(2), 135-146.

Dyess, S. M., \& Sherman R. O. (2009). The first year of practice: New graduate nurses' transition and learning needs. The Journal of Continuing Education in Nursing, 40(9), 403-410.

Fisher, R. A. (1921). On the probable error of a coefficient deduced from a small sample. Metron, 1, 3-32. 
Felton, G. M., \& Parsons, M. A. (1987). The impact of nursing education of ethical/moral decision making. Journal of Nursing Education, 26(1), 7-11.

Fowler, M.D.M. (Ed.). (2008). Guide to the code of ethics for nurses: Interpretation and application. Silver Springs, Maryland: American Nurses Association.

Fowler, M. D., \& Davis, A. J. (2013). Ethical issues occurring within nursing education. Nursing Ethics, 20(2), 126-141. doi:10.1177/0969733012474290

Fowler, M. \& Tschudin, V. (2006). Ethics in nursing: An historical perspective. In A. Davis, V. Tschudin, \& L. de Raeve (Eds.), Essentials of teaching and learning in nursing ethics (pp. 13-25). Philadelphia: Elsevier.

Gastmans, C. Dierckx de Casterle, B., \& Schotsman, P. (1998). Nursing considered as moral practice: A philosophical-ethical interpretation of nursing. Kennedy Institute of Ethics Journal, 8(1), 43-69.

Gaul, A. L. (1987). The effect of a course in nursing ethics on the relationship between ethical choice and ethical actions in baccalaureate nursing students. Journal of Nursing Education, 26(3), 113-117.

Gibson, C. H. (1993). Underpinnings of ethical reasoning in nursing. Journal of Advanced Nursing, 18(3), 2003-2007.

Goethals, S., Gastmans, C., \& Dierckx de Casterle, B. (2010). Nurses' ethical reasoning and behavior: A literature review. International Journal of Nursing Studies, 47(5), 635-650. doi:10.1016/j.ijnurstu.2009.12.010

Görgülü, R. S., \& Dinç, L. (2007). Ethics in Turkish nursing education programs. Nursing Ethics, 14(6), 741-752. 
Ham, K. (2004). Principled thinking: A comparison of nursing students and experienced nurses. The Journal of Continuing Education in Nursing, 35(2), 66-73.

Hamric, A. B. (2001). Ethics development for clinical faculty. Nursing Outlook, 49(3), 115-117. doi:10.1067/mno.2001.116157

Han, S., \& Ahn, S. (2000). An analysis and evaluation of student nurses' participation in ethical decision making. Nursing Ethics, 7(2), 113-123.

Holt, J. \& Long, T. (1999. Moral guidance, moral philosophy, and moral issues in practice. Nurse Education Today, 19(3), 246-249.

Hsu, L. (2011). Blended learning in ethics education: A survey of nursing students. Nursing Ethics, 18(3), 418-430.

Hsu, L., Hsieh, S. (2009). Testing of a measurement model for baccalaureate nursing students' self-evaluation of core competencies. Journal of Advanced Nursing, 65(11), 2454-2463. doi:10.1111/j.1365-2648.2009.05124.x

Hunink, G., van Leeuwen, R., Jansen, M., \& Jochemsen, H. (2009). Moral issues in mentoring sessions. Nursing Ethics, 16(4), 487-498. doi:10.1177/0969733009104611.

Iglesias, M. E. L., Vallejo, R. B. B., Cena, D. P., \& Fuentes, P. S. (2011). Knowledge and positions on bioethical dilemmas in a sample of Spanish nursing students: A questionnaire study. Contemporary Nurse, 38(1-2), 18-23.

Jones, J. M. Nurses top honesty and ethics list for $11^{\text {th }}$ year. Gallop Poll (2010, December). Retrieved from http://www.gallup.com/poll/145043/nurses-tophonesty-ethics-list-11-year.aspx?version=print 
Juujärvi, S., Pesso, K., \& Myyry, L. (2010). Care-based ethical reasoning among firstyear nursing and social services students. Journal of Advanced Nursing, 76(2), $418-427$.

Ketefian, S. (1981). Moral reasoning and moral behavior among selected groups of practicing nurses. Nursing Research, 30(3), 171-175.

Ketefian, S. (1982). Tool development in nursing: Construction of a scale to measure moral behavior. Journal New York State Nurses Association, 13(2), 13-18.

Ketefian, S. (1999). Legal and ethical issues: Ethics content in nursing education. Journal of Professional Nursing, 15(3), 138.

Krawczyk, R. (1997). Teaching ethics: Effect on moral development. Nursing Ethics, $4(1), 57-65$.

Kyle, G. (2008). Using anonymized reflection to teach ethics: A pilot study. Nursing Ethics, 15(1), 6-16. doi:10.1177/3969733007083931

Landry, H., \& Landry, M. (2002). Nursing ethics and legal issues: An integrative approach in nursing education. Journal of Nursing Education, 41(8), 363-364.

Leedy, P. D., \& Ormrod, J. E. (2013). Practical research: Planning and design $\left(10^{\text {th }}\right.$ ed.). Boston, MA: Pearson.

Lemonidou, C., Papathanassoglou, E., Giannakopoilou, M., Patiraki, E., \& Papadatou, D. (2004). Moral professional personhood: Ethical reflections during initial clinical encounters in nursing education. Nursing Ethics, 11(2), 122-137.

Memarian, R., Salsali, M., Vanaki, Z., Ahmadi, F., \& Hajizadeh, E., (2007). Professional ethics as an important factor in clinical competency. Nursing Ethics, 14(2), 203214. 
Mustapha, S. L., \& Seybert, J. A. (1989). Moral reasoning in college students:

Implications for nursing education. Journal of Nursing Education, 28(3), 107111.

Nolan, P. W., \& Markert, D. (2002). Ethical reasoning observed: A longitudinal study of nursing students. Nursing Ethics, 9(3), 243-258.

Numminen, O. H., \& Leino-Kilpi, H. (2007). Nursing students' ethical decision-making: A review of the literature. Nurse Education Today, 27(7), 796-807.

Oddi, L. F., Cassidy, V. R., \& Fisher, C. (1995). Nurses' sensitivity to the ethical aspects of clinical practice. Nursing Ethics, 2(3), 197-209.

Park, M., Kjervik, D., Crandell, J., \& Oerman, M. (2012). The relationship of ethics education to moral sensitivity and moral reasoning skills of nursing students. Nursing Ethics, 19(4), 568-580.

Paulsen, J. E. (2011). Ethics of caring and professional roles. Nursing Ethics 18(2), 201208. doi:10.1177/0969733010392302

Poikkeus, T., Numminen, O., Suhonen, R., \& Leino-Kilpi, H. (2013). A mixed-method systemic review: Support for ethical competence of nurses. Journal of Advanced Nursing, 70(2), 256-271. doi:10.1111/jan.12213

Salkind, N. J. (2011). Statistics for people who (think they) hates statistics. Thousand Oaks, California: SAGE.

Salkind, N. J. (2012). Exploring research ( $8^{\text {th }}$ ed.). Boston, MA: Pearson.

Scanlon, C. (1995). Nursing ethics: Understanding the moral life. Journal of the New York State Nurses Association, 26(1), 16-17. 
Smith, K. V., \& Godfrey, N. S. (2002). Being a good nurse and doing the right thing: A qualitative study. Nursing Ethics, 9(3), 301-312. doi:10.1191/0969733002ne512oa

Tännsjö, T. (2012). Understanding ethics: An introduction to moral theory, (2 ${ }^{\text {nd }}$ ed.). Edinburgh, Scotland: Edinburgh University Press.

Turner, S. L. (1990). An evaluation of the effectiveness of a guided design instructional package on ethical decision making in senior nursing students. (Doctoral dissertation). Retrieved from ProQuest Dissertations and Theses. (UMI No. 1992137390).

Turner, S. L., \& Bechtel, G. A. (1998). The effectiveness of guided design on ethical decision making and moral reasoning among community nursing students. Nursing Connections, 11(1), 69-74.

Ulrich, C. (2012). Nursing ethics in everyday practice. Indianapolis, IN: Sigma Theta Tau International.

Ulrich, C. M., Taylor, C., Soeken, K., O’Donell, P., Farrar, A., Danis, C., \& Grady, C. (2010). Everyday ethics: Ethical issues and stress in nursing practice. Journal of Advanced Nursing Practice, 66(11), 2510-2519. doi:10.1111/j.1365-2648.2010.05425.x

Vanlaere, L., \& Gastmans, C. (2007). Ethics in nursing education: Learning to reflect on care practices. Nursing Ethics, 14(6), 758-766.

Vanlaere, L., \& Gastmans, C. (2011). A personalist approach to care ethics. Nursing Ethics, 18(2), 161-173. doi:10.1177/0969733010388924 
Weaver, K. (2007). Ethical sensitivity: State of knowledge and needs for further research. Nursing Ethics, 14(2), 141-155.

Weaver, K., \& Morse, J. (2006). Pragmatic utility: Using analytical questions to explore the concept of ethical sensitivity. Research and Theory for Nursing Practice: An International Journal, 20(3), 191-214.

Weaver, K., Morse, J., \& Mitcham, C. (2008). Ethical sensitivity in professional practice: Concept analysis. Journal of Advanced Nursing, 62(5), 607-618. doi:10.1111/j.1365-2648.2008.04625.x

Weis, D., \& Shank, M. J. (2000). An instrument to measure professional nursing values. Journal of Nursing Scholarship, 32(2), 201-204.

Wehrwein, T. A. C. (1990). Moral reasoning and ethical decision-making in beginning baccalaureate nursing students. (Doctoral dissertation). Retrieved from ProQuest Dissertations and Theses. (UMI No. 9118949).

Wehrwein, T. (1996). Developing an ethical basis for student-teacher interaction. Journal of Professional Nursing, 12(5), 297-302.

Woods, M. (2005). Nursing ethics education: Are we really delivering the good(s)? Nursing Ethics, 12(1), 5-18. 
Appendix A

Assessment of Individual Characteristics 


\section{Assessment of Individual Characteristic}

1. Please identify your age today.
A. 20-24
B. $25-29$
C. $30-34$
D. $35-39$
E. $40-44$
F. $45-50$
G. $>50$

2. Name of the College of Nursing you are attending.
A. Blessing-Rieman
B. Lakeview
C. St. Francis
D. Peoria Methodist
E. St. Johns
F. St. Anthony

3. Please identify your gender.
A. Male
B. Female

4. Define your marital status.
A. Single-never been married B. Married C. Divorced D. Widowed
E. Not married but in a long-term committed relationship: Approximately how many years

5. Have you ever taken a college course on ethics?
A. Yes
B. No

6. How many hours of college credit have you earned by taking courses with content on ethics?
A. 0
B. 3-6 hrs. (1-2 courses)
C. 7-12 hrs. (3-4 courses)
D. $>12$ hrs. (5 or more courses)

7. What is the level of college credit you have earned? I am earning my BSN and I ....
A. have only completed courses necessary for my BSN
B. also have another Bachelor's degree
C. also have a Master's degree
D. also have a Doctoral degree
E. only have 1- 5 extra courses not required for my BSN

8. Do you have a religious affiliation?
A. Yes
B. No (if no is the answer, proceed to question 10)

9. If you answered yes to question 8; please identify your religion.
A. Roman Catholic
B. Protestant
C. Jewish
D. Muslim
E. Hindi

F. Fundamental Christian

G. Other: Please Specify

10. Of the following ethnic descriptors please identify the one that you associate with yourself.
A. American Indian/Alaska Native
B. Black or African American
C. White/Caucasian
D. Asian
E. Hawaiian or Pacific Islander
F. Mixed-identifying with 2 or more ethnic groups If you identified your ethnic description as mixed, please name the groups:

11. Have you ever been involved in a situation where you were asked to participate in making important or critical decisions about the health care of another individual?
A. Yes
B. No (if no is the answer, proceed to question 13)

12. If the answer to question 11 was yes; what did the decision(s) involve?
A. quality of life
B. termination of life support
C. whether or not to implement treatment
Please share your story about the circumstances of this situation (continue on back of page if needed):

13. Before you entered nursing school, did you work in the health care industry?
A. Yes
B. NO
If yes, what was your position(s)? 
Appendix B

The JAND 


\section{JUDGMENTS ABOUT NURSING DECISIONS 2007 \\ PARTICIPANT VERSION}

Attached are six stories and two scenarios in which nurses find themselves in an ethical dilemma. Various courses of action that a nurse might take to resolve the ethical dilemma are listed following each story.

There are times nurses may believe and think that they should, from a professional point of view, act in a certain manner. However, because of various rules and other limiting factors that exist in an organization they may not always be able to act according to their beliefs and thoughts. Keeping these constraints in mind, you are asked to respond to each action in two ways.

1. Column A Decide if the nurse in the story should, in an ideal situation, carry out each of the described actions or should not take the actions.

2. Column B Decide if nurses on the unit where you work would, given constraints present on the unit or in the organization, be realistically likely to carry out each of the described actions.

Different nurses will have different views on these matters. It is your individual assessment and judgment that is sought about the actions in each of the nursing actions in Column A and Column B. Your answers for each column may be similar or they may be different. The nursing actions listed are not mutually exclusive. A nurse may take one or more actions to resolve ethical dilemmas. If you answer "yes" to one action in a story, you may also answer "yes" or other actions in that story as well.

Please do not write your name on the questionnaire. At no time will your name be identified with any of your answers nor will your individual answers be shared with anyone. 


\section{Story One}

Rebecca and Nancy, good friends, were working on a Pediatric unit. Matthew, a one year old patient, went into heart failure and was transferred to the PICU. Immediately after transfer Rebecca told Nancy that she (Rebecca) had made a medication error and had given Matthew a larger dose of the digoxin than was prescribed. She said that she had not reported the error and did not intend to report it. Rebecca pleaded with Nancy not to say anything to anyone.

For each action below indicate your level of agreement with the nursing action Nancy should take (Column A) and with the nursing

action most nurses are realistically likely to take (Column B) by placing a number in the appropriate box according to the following scale:

\section{$5=$ strongly agree $\quad 4=$ agree $\quad 3=$ neutral $\quad 2=$ disagree $\quad 1=$ strongly disagree}

\section{Column A Column B}

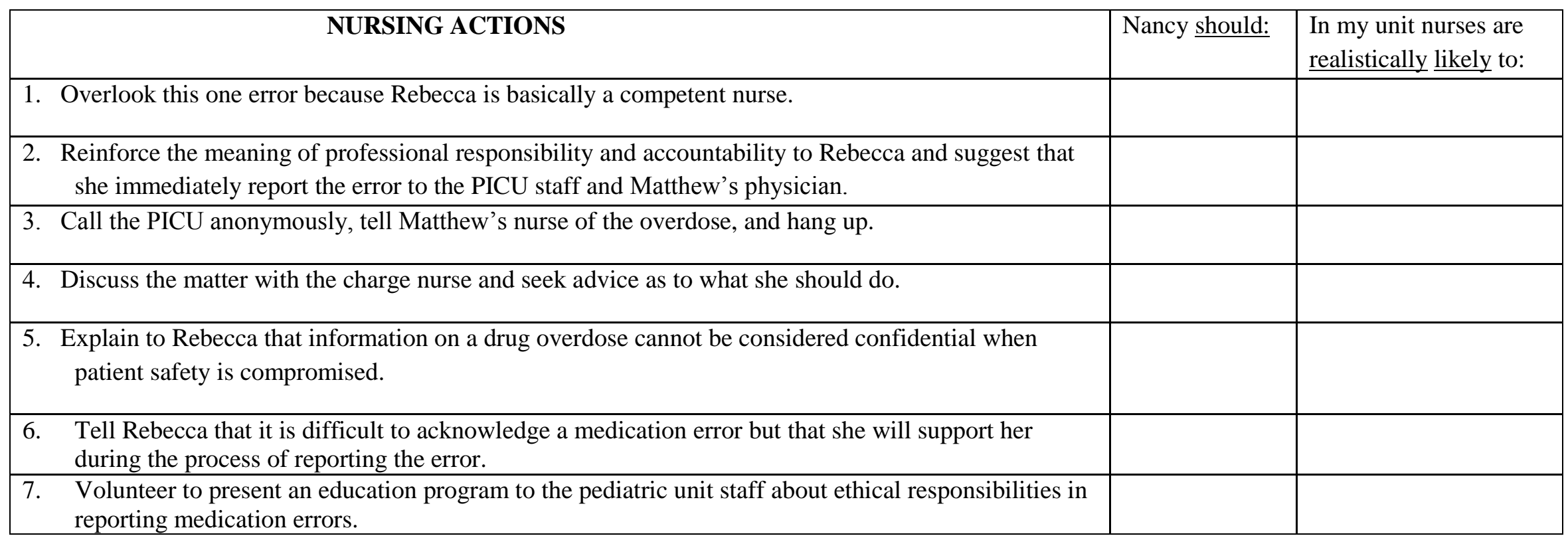

Comments 


\section{Story Two}

Dr. Zimmerman, the chief nephrologist of a community hospital, makes rounds on the dialysis unit visibly intoxicated, appearing disheveled and disorganized. This happens with some regularity. His speech is frequently slurred and inappropriate. Melissa, a staff nurse, has noticed Dr. Zimmerman's behavior for a period of time and has approached both the head nurse of the unit and Dr. Zimmerman's partner to express her concern. She was told by

both of them to mind her own business. Melissa has three school age children and she is the sole support of her family. She lives in a small close-knit community and is aware that Dr. Zimmerman and his wife are good friends with the Vice President of Patient Care and her husband. The community hospital where Melissa works is the only agency where she can work within a 75-mile radius.

For each action below indicate your level of agreement with the nursing action Melissa should take (Column A) and with the nursing action most nurses are realistically likely to take (Column B) by placing a number in the appropriate box according to the following scale:

\section{$5=$ strongly agree $\quad 4=$ agree $\quad 3=$ neutral $\quad 2=$ disagree $\quad 1=$ strongly disagree}

\section{Column A}

Column B

\begin{tabular}{|l|l|l|}
\hline \multicolumn{1}{|c|}{ NURSING ACTIONS } & Melissa should: & $\begin{array}{l}\text { In my unit nurses are } \\
\text { realistically likely to: }\end{array}$ \\
\hline $\begin{array}{l}\text { 1. Call her professional organization or the state board of nursing to discuss her concerns } \\
\text { and seek advice. }\end{array}$ & & \\
\hline $\begin{array}{l}\text { 2. Offer to participate in establishing and implementing a policy and procedure for } \\
\text { reporting and handling impaired practice. }\end{array}$ & & \\
\hline $\begin{array}{l}\text { 3. Do nothing because it is not Melissa's responsibility to monitor medical practice. } \\
\text { 4. Refer patients who complain about Dr. Zimmerman's behavior to Dr. Zimmerman's } \\
\text { partner. }\end{array}$ & & \\
\hline $\begin{array}{l}\text { 5. Speak to Dr. Zimmerman privately and express concern about his health and patient } \\
\text { safety. }\end{array}$ & & \\
\hline $\begin{array}{l}\text { 6. Go to an internet chat room to ask other nurses if they have dealt with such a problem } \\
\text { and what they would advise her to do. }\end{array}$ & & \\
\hline
\end{tabular}

\section{Comments:}




\section{Story Three}

Mr. Ames, 80 years old, has been unconscious in ICU for 6 days after coronary bypass surgery. Efforts to wean him from the ventilator have been unsuccessful due to his history of COPD and poor pulmonary function tests. The cardiovascular surgeon asked Mrs. Ames to sign a consent to perform a tracheotomy on Mr. Ames so he could be transferred out of the ICU as soon as possible to free up a much needed ICU bed. Mr. and Mrs. Ames had discussed their preferences for endof-life care before the surgery. Mrs. Ames expressed her belief that Mr. Ames would view a tracheotomy as an extraordinary measure to preserve his life. She refused to sign the consent. Within the next 24 hours, the cardiovascular resident and the intensivist requested her to sign the permit. Mrs. Ames asked to talk privately to Mike, the RN who had taken care of Mr. Ames during the last 2 days. Mike knew that performing a tracheotomy might prolong Mr. Ames' life and that he would want this to be done, regardless of the quality of life, if this were his father.

For each action below indicate your level of agreement with the nursing action Mike should take (Column A) and with the nursing action most nurses are realistically likely to take (Column B) by placing a number in the appropriate box according to the following scale:

\section{$5=$ strongly agree $\quad 4=$ agree $\quad 3=$ neutral $\quad 2=$ disagree $\quad 1=$ strongly disagree}

Column A

\begin{tabular}{|l|l|l|}
\hline \multicolumn{1}{|c|}{ NURSING ACTIONS } & Mike should: & $\begin{array}{l}\text { In my unit nurses are } \\
\text { realistically likely to: }\end{array}$ \\
\hline $\begin{array}{l}\text { 1. Suggest a multidisciplinary conference with Mrs. Ames, her family, himself and the physician to } \\
\text { discuss the matter. }\end{array}$ & & \\
\hline $\begin{array}{l}\text { 2. Recognize that one's own personal values, in this case Mike's, may be in conflict with those of the } \\
\text { patient and family. }\end{array}$ & & \\
\hline 3. Suggest that Mrs. Ames discuss the matter with the hospital chaplain and offer to call the chaplain. & & \\
\hline $\begin{array}{l}\text { 4. Attend a conference on end-of-life decision-making sponsored by the local hospice association. } \\
\text { 5. Support Mrs. Ames regardless of the decision she makes. }\end{array}$ & & \\
\hline $\begin{array}{l}\text { 6. Discuss Mr. Ames' quality of life with Mrs. Ames so that she understands the importance of } \\
\text { performing a tracheostomy on him. }\end{array}$ & & \\
\hline
\end{tabular}

\section{Comments:}




\section{$\underline{\text { Story Four }}$}

Mr. Gonzales was diagnosed with cancer one year ago and was admitted to the hospital for recurrence of cancer. The oncologist wanted to test an experimental cancer drug on Mr. Gonzales and was trying to convince him that he might be helped by it. The nursing and medical staffs on the unit knew that Mr. Gonzales' questions were not answered fully or truthfully by the oncologist. They knew he wanted to test the drug through further research and was intent on getting Mr. Gonzales as a subject by whatever means. The physician asked Mr. Gonzales to sign a consent form and he was considering signing it because of his prior trust in his oncologist and his fear that saying no would jeopardize his care. He shared these thoughts with his nurse, Hannah. He asked questions about the drug and what he ought to do.

For each action below indicate your level of agreement with the nursing action Hannah should take (Column A) and with the nursing action most nurses are realistically likely to take (Column B) by placing a number in the appropriate box according to the following scale:

\section{$5=$ strongly agree $\quad 4=$ agree $\quad 3=$ neutral $\quad 2=$ disagree $\quad 1=$ strongly disagree}

\section{Column A Column B}

\begin{tabular}{|l|l|l|}
\hline \multicolumn{1}{|c|}{ NURSING ACTIONS } & Hannah should: & $\begin{array}{l}\text { In my unit nurses are } \\
\text { realistically likely to: }\end{array}$ \\
\hline $\begin{array}{l}\text { 1. Tell Mr. Gonzales that it is up to him to decide whether or not to participate in the experimental } \\
\text { research. }\end{array}$ & & \\
\hline $\begin{array}{l}\text { 2. Reassure Mr. Gonzales that his physician is acting in his best interest. } \\
\text { 3. Request a consult from the hospital ethics committee. }\end{array}$ & & \\
\hline $\begin{array}{l}\text { 4. Call and arrange a meeting involving the patient, the oncologist, Mr. Gonzales' primary } \\
\text { physician, and herself so that Mr. Gonzales can have his questions answered. }\end{array}$ & & \\
\hline $\begin{array}{l}\text { 5. Do nothing because this is usually what happens when patients are asked to consent to research. } \\
\text { 6. Inform the human subjects review committee about Mr. Gonzales' concerns. }\end{array}$ & \\
\hline
\end{tabular}

\section{Comments:}




\section{$\underline{\text { Story Five }}$}

It was a holiday weekend on a busy 30-bed pediatric unit with several recent post-op and acutely ill patients. Four registered nurses and one aide were on duty. Everything was under control until 6-year old Kyeisha was admitted as an emergency because the Pediatric ICU was full. She had fallen off some monkey bars and sustained a concussion. She required vital signs and neurological checks every hour. Kyeisha's parents were visibly anxious about her. The nurse in charge,

Jennifer, now felt that the unit was not adequately staffed to provide safe care to all the children. Jennifer called several staff members who were off-duty, but no one was available to come in and work. This was not the first time that short staffing had caused an unsafe situation.

For each action below indicate your level of agreement with the nursing action Jennifer should take (Column A) and with the nursing

action most nurses are realistically likely to take (Column B) by placing a number in the appropriate box according to the following scale:

\section{$5=$ strongly agree $\quad 4=$ agree $\quad 3=$ neutral $\quad 2=$ disagree $\quad 1=$ strongly disagree}

\section{Column A Column B}

\begin{tabular}{|l|l|l|}
\hline \multicolumn{1}{|c|}{ NURSING ACTIONS } & Jennifer should: & $\begin{array}{l}\text { In my unit nurses are } \\
\text { realistically likely to: }\end{array}$ \\
\hline $\begin{array}{l}\text { 1. Ask the resident to move Kyeisha to the pediatric ICU because of her care requirements } \\
\text { and the high patient to staff ratio on the pediatric unit. }\end{array}$ & & \\
\hline $\begin{array}{l}\text { 2. Call the nurse manager at home and tell her that the unit staffing is unsafe. } \\
\text { responsibility if something untoward happens. }\end{array}$ & & \\
\hline $\begin{array}{l}\text { 4. Reassess patient needs and adjust assignments for the present staff to address priorities } \\
\text { given the current situation. }\end{array}$ & $\begin{array}{l}\text { Document her concerns about nurse-patient ratios, present them to the nurse manager, and make } \\
\text { suggestions that might be implemented to supplement staffing in an emergency situation. }\end{array}$ & \\
\hline $\begin{array}{l}\text { 6. After the crisis is over contact the state nurses' association to explore strategies that might be used } \\
\text { to influence changes in staffing patterns within her place of employment. }\end{array}$ & & \\
\hline
\end{tabular}

\section{Comments:}




\section{$\underline{\text { Story Six }}$}

Mrs. Sutton, 60, is an RN. She and her husband had their attorney prepare advance directives for each of them five years ago after they had discussed their wishes with one another and their two adult children, Beth and Peter. Mrs. Sutton did not want any extraordinary measures to sustain her life if there was little hope for recovery of physical and mental functioning. Subsequently she and Mr. Sutton were involved in a car accident; Mr. Sutton was killed instantly and Mrs. Sutton suffered head injuries and a spinal cord injury that left her a quadriplegic. After two weeks Mrs. Sutton suffered multi-organ system failure and the resident approached her children to discuss dialysis. Beth raised concerns about this because of her mother's wishes in her advance directives. Peter became angry and insisted that everything possible be done. Beth asked her mother's nurse, Anne, to tell her brother that he is wrong to override his mother's wishes.

For each action below indicate your level of agreement with the nursing action Anne should take (Column A) and with the nursing

action most nurses are realistically likely to take (Column B) by placing a number in the appropriate box according to the following scale:

\section{$5=$ strongly agree $\quad 4=$ agree $\quad 3=$ neutral $\quad 2=$ disagree $\quad 1=$ strongly disagree}

\section{Column A Column B}

\begin{tabular}{|l|l|l|}
\hline \multicolumn{1}{|c|}{ NURSING ACTIONS } & Anne should: & $\begin{array}{l}\text { In my unit nurses are } \\
\text { realistically likely to: }\end{array}$ \\
\hline $\begin{array}{l}\text { 1. Tell Beth that she cannot mediate family disagreements. } \\
\text { 2. Suggest that Beth and Peter seek advice from the hospital ethics committee. }\end{array}$ & & \\
\hline $\begin{array}{l}\text { 3. Call social work to engage Beth and Peter in a discussion about their own values and those of their } \\
\text { mother as expressed in her advance directives. }\end{array}$ & & \\
\hline $\begin{array}{l}\text { 4. Tell Peter that many physicians are reluctant to carry out advance directives if family members are in } \\
\text { disagreement about what should be done. }\end{array}$ & & \\
\hline $\begin{array}{l}\text { 5. Volunteer to do a question-and-answer presentation on advance directives for her church's senior } \\
\text { citizen group. }\end{array}$ & & \\
\hline 6. Call the legal department for clarification of legal perspectives in such cases. & & \\
\hline
\end{tabular}

\section{Comments:}




\section{Scenario One}

Jamal, a registered nurse, has been invited to serve on a committee being formed by the American Nurses Association to examine conditions and environments for practice. She is attending graduate school part-time, has a baby daughter, and works full-time. She is very interested in this opportunity but finds herself in a quandary.

For each action below indicate your level of agreement with the nursing action Jamal should take (Column A) and with the nursing

action most nurses are realistically likely to take (Column B) by placing a number in the appropriate box according to the following scale:

$5=$ strongly agree $\quad 4=$ agree $\quad 3=$ neutral $\quad 2=$ disagree $\quad 1=$ strongly disagree

\section{Column A Column B}

\begin{tabular}{|l|l|l|}
\hline \multicolumn{1}{|c|}{ NURSING ACTIONS } & Jamal should: & $\begin{array}{l}\text { In my unit nurses are } \\
\text { realistically likely to: }\end{array}$ \\
\hline 1. Ask for a month to make a decision because it is an opportunity she is interested in. & & \\
\hline $\begin{array}{l}\text { 2. Decline because of her work and family responsibilities. } \\
\text { than her own unit or even her state. }\end{array}$ & & \\
\hline $\begin{array}{l}\text { 3. Appreciate that this type of participation helps shape social policy at a broader level } \\
\text { organization is crucial to the advancement of the profession. }\end{array}$ & & \\
\hline $\begin{array}{l}\text { 5. Agree to participate despite her other obligations. } \\
\text { 6. Discuss, with her academic advisor, the possibility that serving on this committee } \\
\text { could enable her to do a project for one of her courses, thus achieving two things at } \\
\text { once. }\end{array}$ & & \\
\hline
\end{tabular}

\section{Comments:}




\section{$\underline{\text { Scenario Two }}$}

Jason is working on a unit where nursing faculty of the affiliated nursing school conduct nursing research on patient care problems. One of the faculty investigators meets with the nursing staff to offer them the opportunity to join her research team.

For each action below indicate your level of agreement with the nursing action Jason should take (Column A) and with the nursing action most nurses are realistically likely to take (Column B) by placing a number in the appropriate box according to the following scale:

\section{$5=$ strongly agree $\quad 4=$ agree $\quad 3=$ neutral $\quad 2=$ disagree $\quad 1=$ strongly disagree}

\section{Column A Column B}

\begin{tabular}{|l|l|l|}
\hline \multicolumn{1}{|c|}{ NURSING ACTIONS } & Jason should: & $\begin{array}{l}\text { In my unit nurses are } \\
\text { realistically likely to: }\end{array}$ \\
\hline 1. Focus all his efforts on taking care of patients because that is his sole responsibility. & & \\
\hline $\begin{array}{l}\text { 2. Volunteer to assist because he is planning to start graduate school to learn more about } \\
\text { scholarly approaches to patient care. }\end{array}$ & & \\
\hline $\begin{array}{l}\text { 3. Use this opportunity to acquire research skills that can result in improved patient care. } \\
\text { 4. Participate when he has a slow day. }\end{array}$ & & \\
\hline $\begin{array}{l}\text { 5. Decline because staff nurses don't have the time or knowledge to contribute to } \\
\text { nursing research efforts. }\end{array}$ & & \\
\hline
\end{tabular}

\section{Comments:}

